\title{
A Meta-Analysis of Line Bisection and Landmark Task Performance in Older Adults
}

\author{
Gemma Learmonth $^{1}$ (D) Marietta Papadatou-Pastou ${ }^{2,3}$ (D)
}

Received: 19 June 2020 / Accepted: 5 April 2021 / Published online: 22 April 2021

(c) The Author(s) 2021

\begin{abstract}
Young adults exhibit a small asymmetry of visuospatial attention that favours the left side of space relative to the right (pseudoneglect). However, it remains unclear whether this leftward bias is maintained, eliminated or shifted rightward in older age. Here we present two meta-analyses that aimed to identify whether adults aged $\geq 50$ years old display a grouplevel spatial attention bias, as indexed by the line bisection and the landmark tasks. A total of 69 datasets from 65 studies, involving 1654 participants, were analysed. In the meta-analysis of the line bisection task $(n=63)$, no bias was identified for studies where the mean age was $\geq 50$, but there was a clear leftward bias in a subset where all individual participants were aged $\geq 50$. There was no moderating effect of the participant's age or sex, line length, line position, nor the presence of left or right cues. There was a small publication bias in favour of reporting rightward biases. Of note, biases were slightly more leftward in studies where participants had been recruited as part of a stand-alone older group, compared to studies where participants were recruited as controls for a clinical study. Similarly, no spatial bias was observed in the meta-analysis of the landmark task, although the number of studies included was small $(n=6)$. Overall, these results indicate that over 50 s maintain a group-level leftward bias on the line bisection task, but more studies are needed to determine whether this bias can be modulated by stimulus- or state-dependent factors.
\end{abstract}

Keywords Spatial attention $\cdot$ Pseudoneglect $\cdot$ Aging $\cdot$ Line bisection $\cdot$ Landmark task $\cdot$ HAROLD model

\section{Introduction}

Healthy young adults exhibit a consistent, group-level, lateralised asymmetry of spatial attention favouring the left side of space ("pseudoneglect", Bowers \& Heilman, 1980). This phenomenon typically results in an overestimation of features located within the left hemispace relative to the right, such as the size (Nicholls et al., 1999), number (Luh, 1995), and the luminance of objects (Mattingley et al., 1994) as well as their spatial frequency (Niemeier et al., 2007). In contrast, many studies in older adults (usually aged 50-60 years upwards) report a different pattern of spatial attention,

Gemma Learmonth

Gemma.Learmonth@glasgow.ac.uk

1 Institute of Neuroscience \& Psychology, University of Glasgow, Glasgow, Scotland

2 School of Education, National and Kapodistrian University of Athens, Athens, Greece

3 Biomedical Research Foundation, Academy of Athens, Athens, Greece with group-level lateralised biases either eliminated entirely (Failla et al., 2003; Learmonth et al., 2017) or mirrored, favouring the right hemispace in a pattern similar to that observed in hemispatial neglect (Benwell et al., 2014; Fujii et al., 1995; Fukatsu et al., 1990; Schmitz \& Peigneux, 2011; Stam \& Bakker, 1990). However, other studies have reported a maintained leftward pseudoneglect bias in this older group (Beste et al., 2006; Brooks et al., 2016; Hatin et al., 2012; Varnava \& Halligan, 2007). A meta-analysis of pseudoneglect performed 20 years ago by Jewell and McCourt (2000) identified that spatial biases were indeed more rightward in adults aged over 50 years old compared to those aged under 40 . Yet, there remains considerable debate regarding whether spatial biases are maintained leftward or shifted rightward in the older population or whether such a bias exists at all (Friedrich et al., 2018).

Our understanding of these possible age-related changes in behavioural measures of spatial bias is important because these measures are often used as a proxy measurement of lateralised neural activity within the brain. Specifically, pseudoneglect is considered to be a manifestation of right 
posterior parietal dominance for spatial attention, thus directing our attention to the contralateral left hemispace (Benwell et al., 2014; Çiçek et al., 2009; Fink et al., 2001; Foxe et al., 2003). As such, a rightward shift of spatial bias in older adults could potentially represent an age-related reorganisation or repurposing of the brain regions that are responsible for spatial processing. On the contrary, if older adults exhibit a maintained pseudoneglect, then this could indicate that spatial attention is not susceptible to the same aging processes that affect other cognitive functions. For example, empirical findings in the working memory domain have led to the development of various theoretical frameworks to account for observed patterns of cortical reorganisation in the elderly. By extending these frameworks to spatial processing, we may be led to conclude that an eliminated or mirrored spatial bias indicates that the right hemisphere undergoes a process of accelerated aging relative to the left (the right hemi-aging model; Goldstein \& Shelly, 1981). Alternatively, eliminated spatial biases could represent hemispheric asymmetry reduction in older adults (the HAROLD model; Cabeza et al., 1997), where brain functions that are lateralised in young adults become less lateralised in older age. Later modifications of the HAROLD model proposed that contralateral neural resources (i.e., left-hemispheric in this case) may be specifically co-opted in order to support behavioural performance (Cabeza et al., 2002; Dolcos et al., 2002). In addition to deepening our knowledge of how the brain ages, given that altered lateralised spatial processing in the elderly has been linked to an increased risk of falls (Nagamatsu et al., 2009, 2011, 2013), our understanding of these group-level changes of spatial bias in seniors could potentially represent a simple method of identifying at-risk individuals. Moreover, identifying any age-related changes in neural activation should allow for a more targeted approach to the delivery of non-invasive brain stimulation and neurofeedback therapies (Learmonth et al., 2015b).

Although there appears to be some potential in linking spatial biases to lateralised neural activity at an individual level, and further to 'real-world' behaviours, it is important to emphasise that the bulk of research in this area describes spatial biases at the group level, with few studies focusing on individual differences (although see Benwell et al., 2013; McCourt, 2001; Newman et al., 2014; Szczepanski \& Kastner, 2013). It is also important to highlight that the spatial biases that are observed in individual healthy adults are subtle, often representing only a few millimetres of deviation from the veridical midpoint of a bisected line. This is particularly apparent in comparison to the large right-sided biases observed in patients with hemispatial neglect (Halligan et al., 1990). Large variations in the range of biases are typically observed within age groups, both in terms of bias direction and magnitude, and there is often considerable overlap when comparing young and older adults directly (see Friedrich et al., 2016; Learmonth et al., 2018). Thus, some older adults exhibit a leftward bias that is similar to, or indeed even larger, than young adults. Conversely, some young adults exhibit a large rightward bias that is consistent across testing days (Learmonth et al., 2015a). As such, it is important not to over-interpret small group-level changes of bias in terms of possible cortical reorganisation of spatial attention in older adults, when the conclusions may not be applicable to all, or even the majority of individuals within the group.

One potential source of the heterogeneity described above is the range of tasks that are administered to quantify spatial biases (Failla et al., 2003; Friedrich et al., 2018). The line bisection task, which involves participants indicating the midpoint of a horizontally presented line, is most prevalent across the literature. Given the simplicity of the line bisection task, it is often used at the hospital bedside in the diagnosis of hemispatial neglect (Schenkenberg et al., 1980). The landmark task is a non-motor adaptation of the line bisection task, where participants indicate whether the left or right side of a pre-bisected line is shorter or alternatively whether the bisection mark is closer to the left or right end of the line (Milner et al., 1992). Other tasks are also used to assess spatial biases, including the greyscales task (Mattingley et al., 1994), gratingscales task (Niemeier et al., 2007), chimeric faces (Levy et al., 1972), and lateralised visual detection (Learmonth et al., 2015a). However, we have shown in young adults that although individual tasks elicit consistent measures of spatial bias over time, the direction and magnitude of biases do not necessarily correlate across the different tasks (Learmonth et al., 2015a, 2018; Luh, 1995; Nicholls et al., 1999). We have also recently identified a similar pattern of good intra-, but poor inter-task consistency in older adults aged over 60 years old (Märker et al., 2019). Further compounding this heterogeneity, it is likely that subtle variations in the stimulus properties presented within each task place varying cognitive demands on participants, leading to stimulus-induced shifts of spatial bias, for example line length (Benwell et al., 2014; Mennemeier et al., 2001), the spatial position of the line (McCourt et al., 2000; McCourt \& Jewell, 1999) and the presence of lateralised cues (McCourt et al., 2005; Mennemeier et al. 1997). Participant characteristics such as sex (Chen \& Goedert, 2012; Pierce et al., 2003) and handedness (De Agostini et al., 1999; Failla et al., 2003), and endogenous states, such as transient alertness levels (Dufour et al., 2007; Manly et al., 2005) are also likely to influence spatial biases, perhaps even in an additive manner (Benwell et al., 2014; McCourt \& Jewell, 1999).

In summary, it remains unclear whether older adults, as a group, exhibit maintained pseudoneglect, an eliminated spatial bias, or a preference for the right hemispace when tested with the line bisection and landmark tasks. Here, we report the results of an updated and enriched meta-analysis of the literature to date, given that a substantial number of studies have been conducted since the meta-analysis of Jewell and McCourt (2000). The principal question is whether older adults, aged $\geq 50$ years old, have a spatial attention bias that 
is statistically different to zero (i.e., no bias to either side of space). Due to the range of tasks that are used to measure spatial biases, and the problematic nature of comparing the biases obtained across different tasks, we chose to focus only on the line bisection and the landmark tasks. Secondly, in order to maximise the number of datasets in the metaanalysis, we included data from healthy older adults who had been recruited as control samples in clinical studies. We also aimed to assess the moderating influence of age, sex, line position, the presence of lateralised cues, and the type of task presented. Finally, we determined whether small study bias, a form of publication bias, has affected the reporting of spatial biases in older adults within the wider literature.

\section{Method}

The protocol for the meta-analysis was pre-registered on Open Science Framework prior to conducting the literature searches (https://osf.io/d97qc/).

Studies were identified from literature searches using the PsycINFO, Web of Science and Scopus electronic databases, from inception until $12^{\text {th }}$ January 2021 . The search terms ("landmark task" OR "line bisection") AND ("aging" OR "ageing" OR "older") were used, targeting all fields. After rejecting duplicate records, 1620 unique abstracts were screened for potential inclusion using the criteria listed in the "Study selection" section below. The full text of 211 articles was examined to assess for eligibility and 65 studies (comprising a total of 69 datasets) were identified as eligible for inclusion in the meta-analysis. The available data was extracted, cross-checked by a second reviewer and any discrepancies were resolved by consultation with a third reviewer.

Additional information was obtained by email correspondence for 8 studies where there was insufficient data reported to calculate effect sizes (Benwell et al., 2014; Beste et al., 2006; Ellis et al., 2006; Jeong et al., 2006; Laudate et al., 2013; Luauté et al., 2012; Vallar et al., 2000; Veronelli et al., 2014a). A further 18 studies may have been eligible for inclusion but the requested data was either not available, the authors failed to respond, or contact details were no longer valid (Andrade et al., 2013; Baheux et al., 2007; Bailey et al., 2000; Bourne \& Gray, 2009; Costantini et al., 2014; Ebersbach et al., 1996; Gutiérrez Pérez et al., 2011; Harvey et al., 1995a; Kim et al., 2011; Lee et al., 2010, 2001; Luvizutto et al., 2020; Olk et al., 2004; Pizzamiglio et al., 1990, 2000; Wang et al., 2005; ReuterLorenz \& Posner, 1990; Rousseaux et al., 2006). In contravention of our pre-registration we did not contact authors to ask for unpublished studies due to time constraints. Details of the search process are documented in Fig 1. The PRISMA statement (Moher et al., 2009) on reporting items for systematic reviews and meta-analyses was followed.

\section{Study Selection}

The criteria for inclusion of a study in the meta-analysis were as follows:

1. Age: Studies were included if the participant sample consisted of adults aged $\geq 50$ years old. Studies were excluded if the age range included any participants aged $<50$ years old. If no age range was reported, but the mean age was $\geq 50$, the study was included.

2. Clinical status: Studies were included if the participants were healthy individuals. We also included studies if the participants formed a control group that had been recruited as a comparator to a clinical group, for example hemispatial neglect (e.g., Halligan et al., 1990) and dementia (e.g., Almkvist et al., 1992), but only the data on the healthy controls were used for the purposes of the meta-analysis. Studies where the control group were themselves part of a clinical population (e.g., hospital inpatients; Schenkenberg et al., 1980) were excluded.

3. Task: Studies were included where visuospatial bias was assessed using standard versions of either the line bisection task or the landmark task. Non-standard versions, such as gap bisection (e.g., Balconi et al., 2013), sentence bisection (Arduino et al., 2016), and rods that were bisected via tactile exploration (Brooks et al., 2011), were excluded. Only lines presented horizontally were included, and those presented vertically (e.g., Lee et al., 2002) or radially (e.g., Barrett \& Craver-Lemley, 2008) were excluded.

4. Language: Only studies written in English were included.

\section{Moderators}

The following moderator variables were examined in the meta-analysis:

1. Age: The numerical mean age of participants in each study was included as a continuous variable. All of the studies that were included reported the mean age, except three. The control participants in Grossi et al. (1999) were the "same age [] as the patients" (i.e., 50-69 years old). Similarly, Luauté et al. (2012) did not report a mean age for their control participants, but recruited "six healthy subjects and five patients aged between 67 and 80 years old". Van Deusen (1983) was included although the author reported that 1 of the 93 participants may have been aged $<50$ (although this was considered unlikely). Finally, as an exploratory follow-up, an overall effect calculation was performed separately for studies where all participants were known to be aged at least 50 


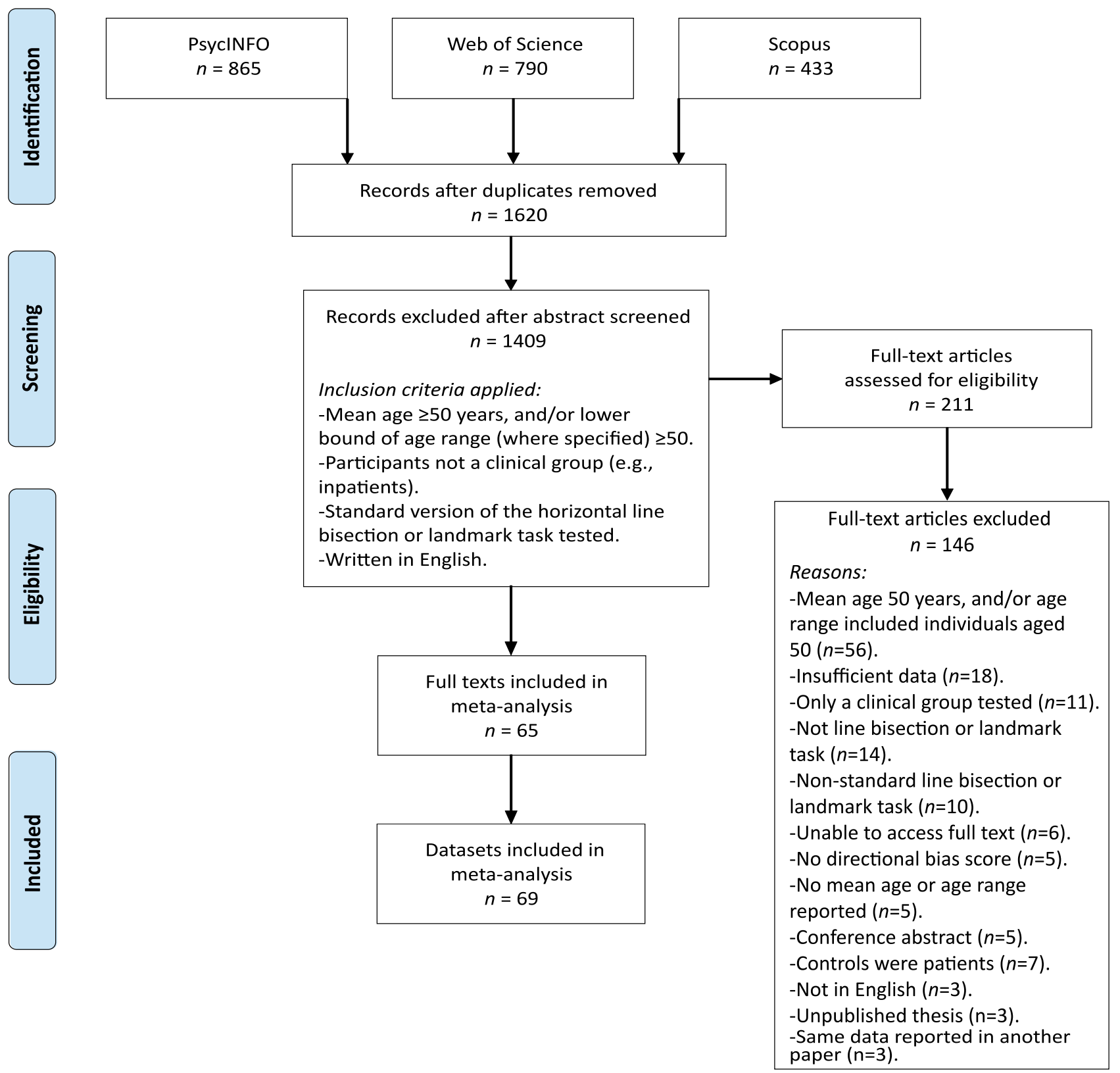

Fig. 1 Flow diagram documenting the electronic database searches, the screening of study abstracts and full-texts, and the reasons for excluding studies. Adapted from Preferred Reporting Items for Systematic Reviews and Meta-Analyses: The PRISMA Statement (Moher et al., 2009)

and for studies where the age range of participants was not reported and the two models were then compared.

2. Sex: Nine studies reported separate data for men and women (Barrett et al., 2002; Barrett \& Craver-Lemley, 2008; Beste et al., 2006; De Agostini et al., 1999; Halligan et al., 1990; Learmonth et al., 2018; Muayqil et al., 2019; Pierce et al., 2003; Varnava \& Halligan, 2007). Since the majority of studies did not report spatial biases separately for male and female participants, we also calculated the percentage of male participants in each study where this data was available. Nineteen studies did not report the sex of their partici- pants and the data from the following studies were therefore not included in this analysis (Andrews et al., 2017; Barton et al., 1998; Binetti et al., 2011; Corazzini et al., 2005; Daini et al., 2008; Doricchi et al., 2002; Gassama et al., 2011; Grossi et al., 1999; Hatin et al., 2012; Luauté et al., 2012; Mennemeier et al., 1997, 2001; Plummer et al., 2006; Richard et al., 2004; Striemer \& Danckert, 2010; Vallar et al., 2000; Veronelli et al., 2014b; Williamson et al., 2018; Zeller \& Hullin, 2018).

3. Hand used: The hand that was used to bisect the line was experimentally tested in five studies, the left and 
right hands in Beste et al. (2006), De Agostini et al. (1999), Hatin et al. (2012) and Jeong et al. (2006), and the left, right, and both hands simultaneously in Failla et al. (2003).

4. Line length: Eleven studies reported spatial biases separately for more than one line length (Benwell et al., 2014; Binetti et al., 2011; Cowey et al., 1994; Ellis et al., 2006; Halligan et al., 1990; Kasai et al., 2016; Learmonth et al., 2017; Potter et al., 2000; Richard et al., 2004; Vallar et al. 2000; Varnava \& Halligan, 2007). The visual angle of each line was extracted, or calculated manually from the line length and the viewing distance when the visual angle was not reported. As per Jewell and McCourt (2000) a viewing distance of $45 \mathrm{~cm}$ was assumed where the viewing distance was unavailable. Eight studies reported data from three or more line lengths (Benwell et al., 2014; Binetti et al., 2011; Cowey et al., 1994; Ellis et al., 2006; Halligan et al., 1990; Richard et al., 2004; Vallar et al., 2000; Varnava \& Halligan, 2007). To aid the comparison between long and short lines, we selected only the longest and shortest lines that were reported in these studies, rather than calculating an average across a range of lengths. This resulted in a mean long line length of $25.16^{\circ}$ and short line length of $5.18^{\circ}$, which corresponds with the allocation of long lines as $\geq 17.68^{\circ}$ and short lines as $\leq 16.44^{\circ}$ in Jewell and McCourt (2000). A further 4 studies reported data from multiple line lengths but were not included in the line length analysis, as the lines were either all short or all long according to our criteria (Barrett et al., 2002; Barton et al., 1998; Drago et al., 2008a; Veronelli et al., 2014a).

5. Spatial position: The horizontal spatial position of the line was examined in 9 studies (Beste et al., 2006; Ellis et al., 2006; Jeong et al., 2006; Learmonth et al., 2018; Mennemeier et al., 1997, 2001 [experiments 1 and 2]; Potter et al., 2000; and Williamson et al., 2018). Data was extracted for lines that were positioned to the left and right of the participant's midline.

6. Cues: Seven studies presented lateralised cues that aimed to direct attention to the left or right hemispace during the line bisection task. This primarily involved the presentation of a stimulus located at the left or right ends of the line (a letter: Harvey et al., 1995b; 2000; a letter or number: Mennemeier et al., 1997; dots: Drago et al., 2008a, 2008b; circles: Williamson et al., 2018), or where a section of the line was thicker at one end (Falchook et al., 2015). Three additional studies reported data for cued bisections but were excluded, one where no means or standard deviations were available (Chieffi et al. 2014), one which involved a horizontally moving background (Choi et al., 2007), and another which involved Müller-Lyer illusion lines (Olk et al., 2001).

7. Control group status: Finally, we assessed whether the participant recruitment context had an effect on spatial bias. Specifically, whether biases differed in participants who were recruited as control participants within a clinical study, compared to those recruited as a stand-alone healthy older participant group. Forty-two datasets that were included in the analysis had tested an older control group as part of a clinical study, and 22 datasets had tested a stand-alone group of healthy older adults.

In addition to these 7 moderator variables, as per our preregistered protocol we also extracted data for the handedness of participants, the modality of presentation (paper and pencil or computerised), the salience of the line, eye of regard (binocular or uniocular), gaze direction, scanning direction, and body orientation. We either did not find enough data to perform analyses on these moderator variables or in the case of handedness the majority of studies had exclusively recruited right-handed participants (44 of the 49 studies that reported participant handedness). The raw data for these moderators and analysis code is available on Open Science Framework at https://osf.io/rme53/.

\section{Effect Size Estimates}

As per convention, leftward biases were denoted by a negative value and rightward biases with a positive value. The mean bias scores and standard deviations were converted to effect size estimates using the formula:

Cohen's $d=$ mean $/ S D$

In cases where studies reported the mean bias and standard deviations for multiple experimental factors (e.g., sex, line lengths) rather than an overall mean bias, the effect sizes were calculated separately for each factor and subsequently averaged to create an aggregate effect size. In a few cases (Daini et al., 2008; Harvey et al., 2000, 1995b; Schmitz \& Peigneux, 2011; Veronelli et al., 2014b; Williamson et al., 2019), only the $t$-value obtained from a one-sample $t$-test against chance was reported and this was used to calculate Cohen's $d$ using the formula:

Cohen's $d=t / \operatorname{sqrt}(n)$

In other cases, the standard deviation was calculated first from reported confidence intervals (Andrews et al., 2017) or standard errors (Plummer et al., 2006; Striemer \& Danckert, 2010; Williamson et al., 2018) before proceeding to the effect size calculation. The rationale for the decisions taken in each study are reported in Table 1. 


\section{Statistical Analysis}

The metafor (Viechtbauer, 2007) and robumeta (Fisher et al., 2017) software packages for $\mathrm{R}$ were used for the analysis. A single, overall analysis was not possible, due to the fact that two different tasks were used in the datasets (line bisection and landmark) in quite unequal numbers (63 and 6 , respectively). Moreover, two of the datasets reported data on the same participants for the two tasks (Harvey et al., 2000; Learmonth et al., 2018), violating the independence of data points. Therefore, the two tasks were analysed separately and their overall effect sizes were then compared.

First, for each of the datasets, the effect size was calculated as described above. Then, for each of the two analyses an overall effect size estimate was calculated by weighting each dataset effect size according to sample size (an index of study precision), using a random-effects model along with a test for the overall effect ( $Z$ statistic with corresponding $p$-value). Heterogeneity was then tested using three tests: the $Q$ statistic (with its corresponding $p$-value), the $I^{2}$ index, and the Tau ${ }^{2}$ statistic. The $I^{2}$ index levels can be described as low, moderate, and high, when they fall close to $25 \%, 50 \%$, and $75 \%$ respectively (Higgins et al., 2003). The overall effect sizes calculated for the two tasks were then compared using the $Q$ statistic (with corresponding $p$-value).

In order to investigate the presence of publication bias we used the funnel plot graphical test, Egger's $t$ statistical test, and Duval and Tweedie's (2000) trim and fill method of correcting bias. A moderator variables analysis was further deemed necessary, as the heterogeneity found may be caused by the presence of moderator variables. This analysis was performed only within the line bisection group of studies, that included a sufficient number of datasets to justify such an analysis. For continuous moderator variables (i.e., age and percentage of male participants) meta-regression was used, using a random effects model (method of moments), with evaluation in terms of the $Q$ statistic, $R^{2}$ (and $p$-value). When examining the effects of the categorical moderator variables (i.e., sex, line length, presence of lateralised cues, line position, and control group status) the average effect sizes in the different subgroups that form the levels of the moderator were compared again by means of the $Q$ statistic (and $p$-value). Forest plots and funnel plots were used to depict the information visually.

\section{Results}

A total of $k_{t}=65$ studies were included in the two metaanalyses, comprising $k_{d}=69$ separate datasets and total$\operatorname{ling} n_{t}=1654$ individuals. Details of individual studies and moderator variables are shown in Tables 1 and 2 .

\section{Overall Effect Estimates}

Line Bisection Task: A total of $k_{d}=63$ datasets (from $k_{t}=$ 61 studies) were included in the analysis, totalling $n_{t}=1480$ individuals. A random effects model was employed, which gave a weighted average of the effect sizes across all datasets of $d=-.02$, and $95 \%$ confidence interval $(95 \% \mathrm{CI})$ of -.13 , .008 , with no statistical evidence of a bias to either side of space, $Z=-.44, p=.66$ (Fig 2). The Egger's $t$-test, revealed evidence of small study publication bias, $t(61)=2.13, p=$ .04 , as did the visual inspection of the funnel plot (see Fig 3 ). According to the trim and fill test for random effects, 10 studies will need to be imputed to the left of the mean, corresponding to a smaller $d$, in order for the funnel plot to be symmetrical, in which case the effect size would be $d=$ $-.16,95 \% \mathrm{CI}=-.32, .01$.

Landmark Task: A total of $k_{d}=6$ datasets (from $k_{t}=6$ studies) were included in the analysis, totalling $n=174$ individuals. A random effects model gave a weighted average of the effect sizes across all datasets of $d=.12,95 \% \mathrm{CI}=-.17$, $.41, Z=.82, p=.42$ (Fig 4). In other words, we did not find evidence of a bias in the landmark task. Due to the small number of studies included in this analysis, the findings must be interpreted with caution. Moreover, no publication bias analysis or moderator variables analysis was justified.

\section{Comparison Between the Line Bisection and the Landmark Task}

The 63 datasets that used the line bisection task were compared to the 6 datasets that used the landmark task. Of note, two of the studies (Harvey et al., 2000; Learmonth et al., 2018) administered the task to the same participants, therefore not all data points were independent. No statistical evidence of a difference between the two tasks was found, $Q$ $(1)=.85, p=.36$. Again, due to the small number of studies that used the landmark task, caution is necessary when interpreting findings.

\section{Analysis of Moderator Variables: Line Bisection Task}

The moderate inconsistency within the line bisection task datasets led us to test the possible moderating effect of age, line length, sex, the spatial position of the line, the presence of right of left lateralized cues and the control group status of the participants. Only the datasets that reported the information needed were included.

1. Age: The mean age of participants across all 63 datasets was 69.2 years. Meta-regression of the mean age of 


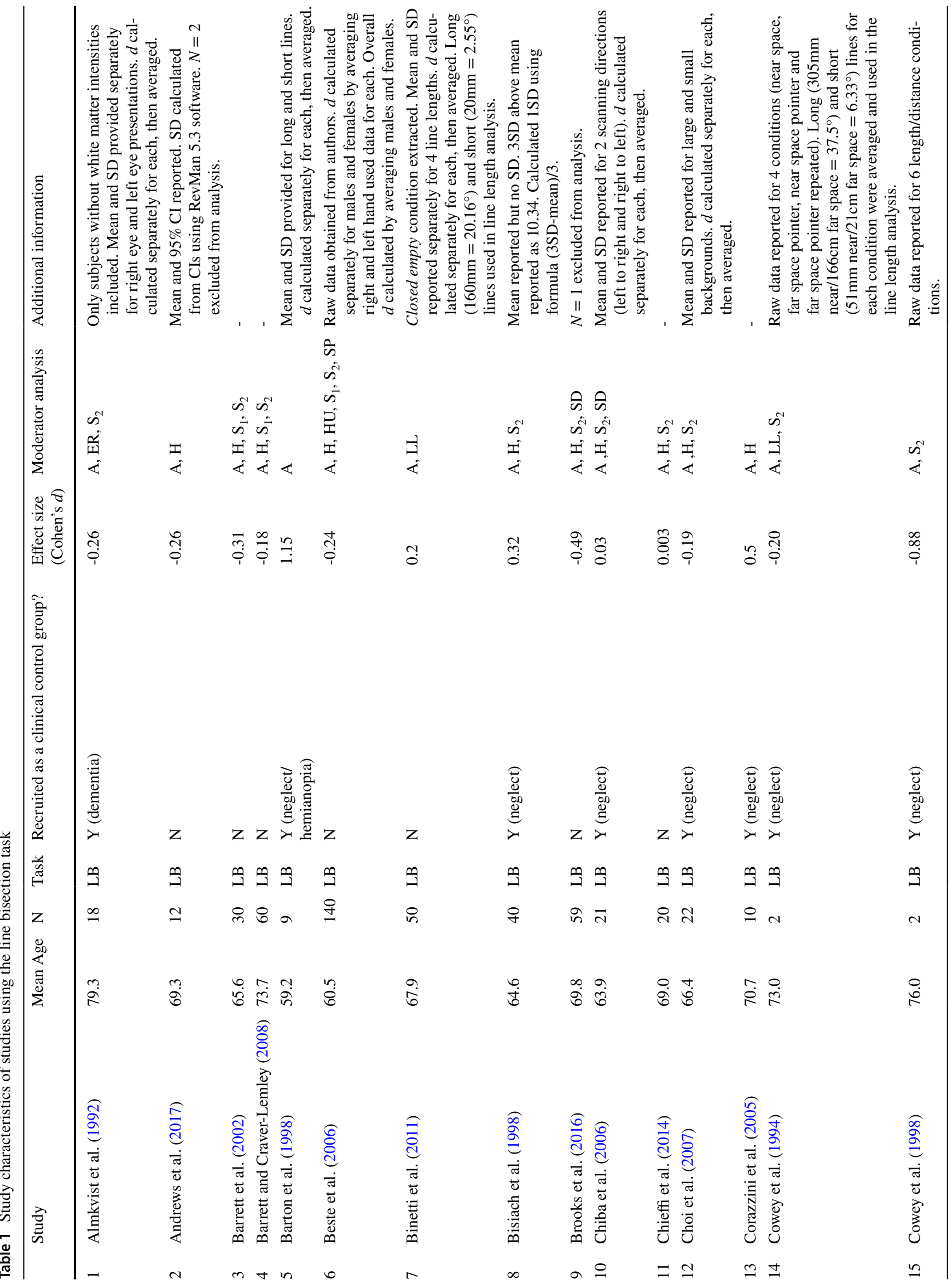




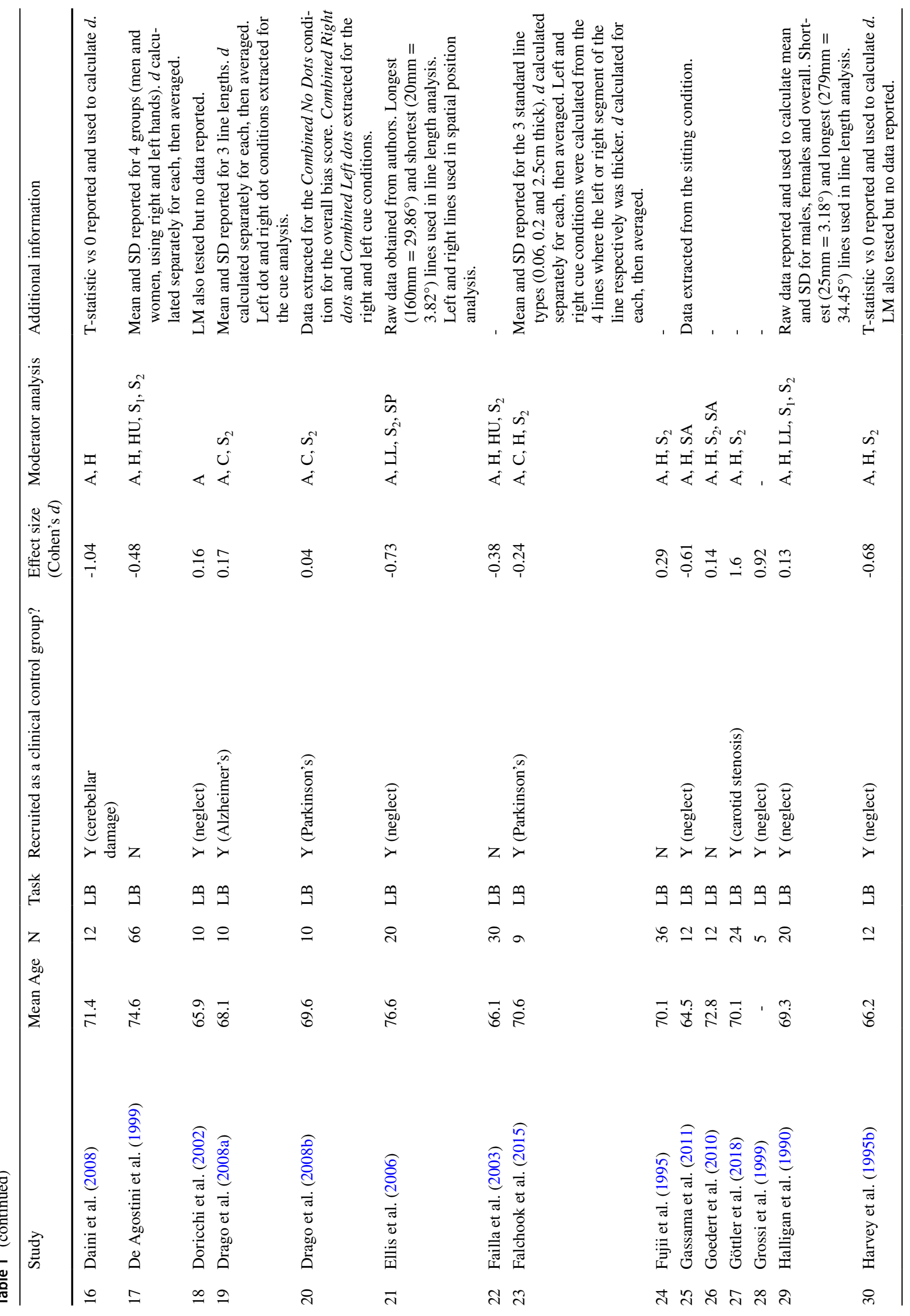




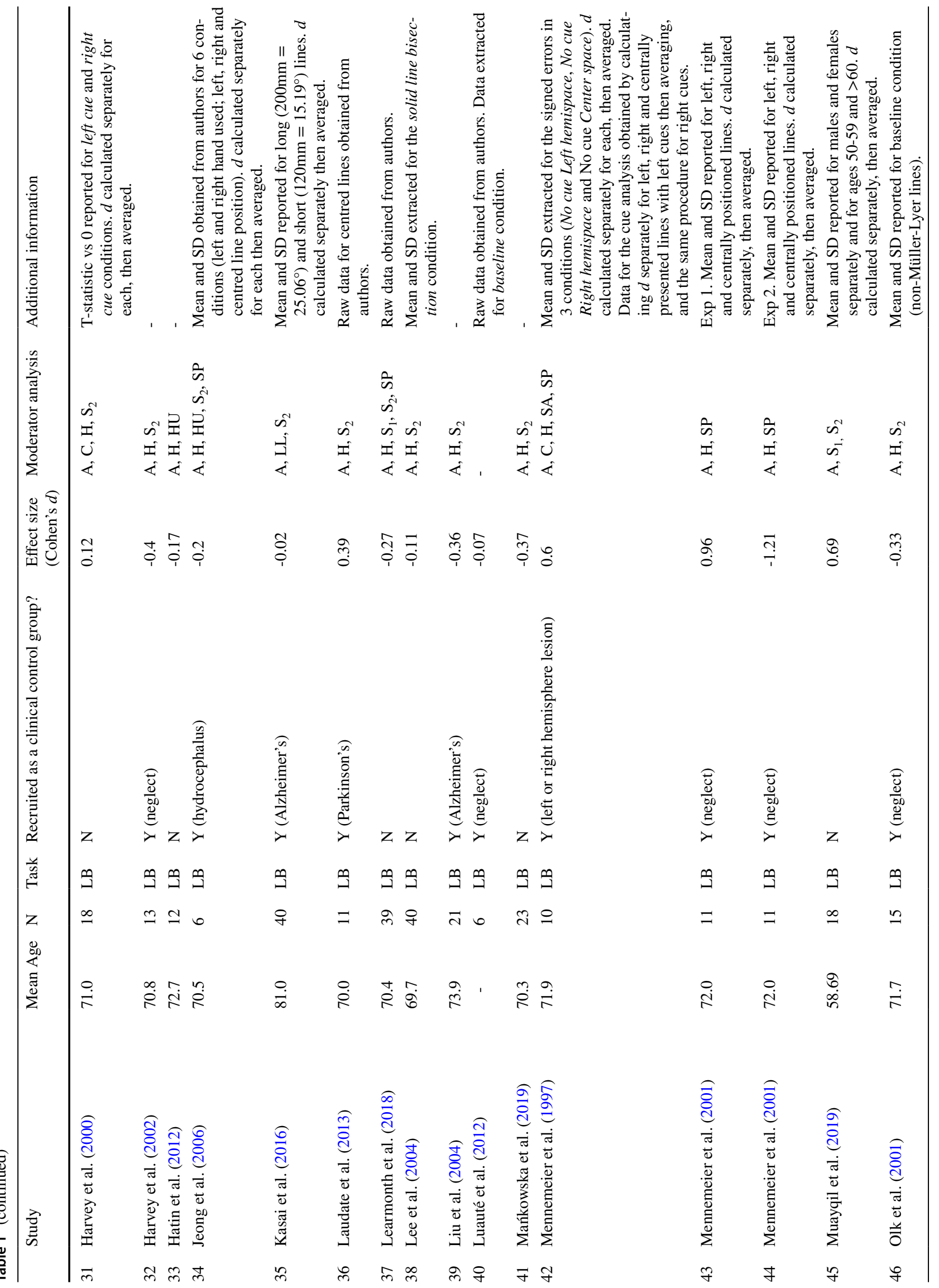




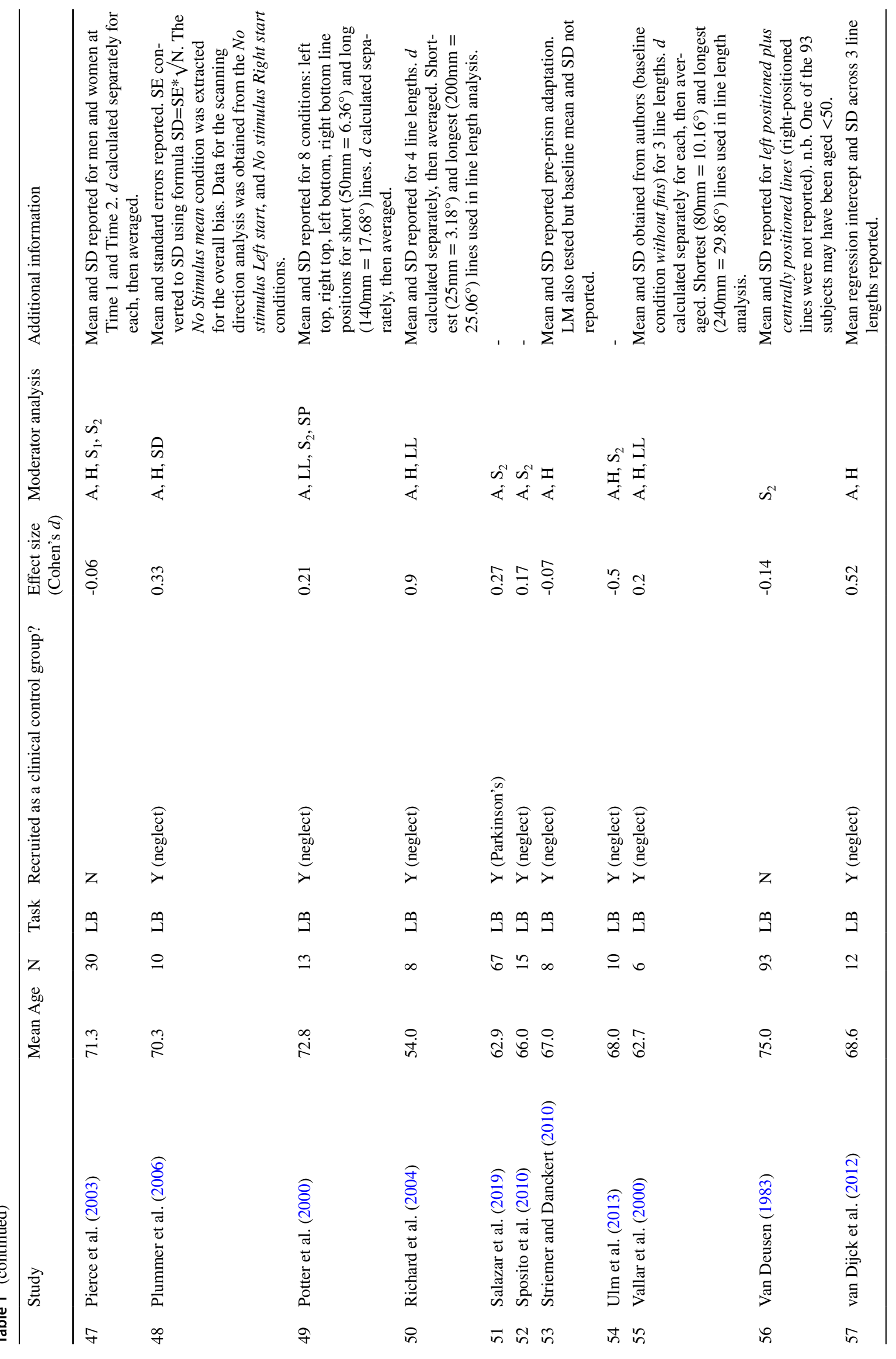




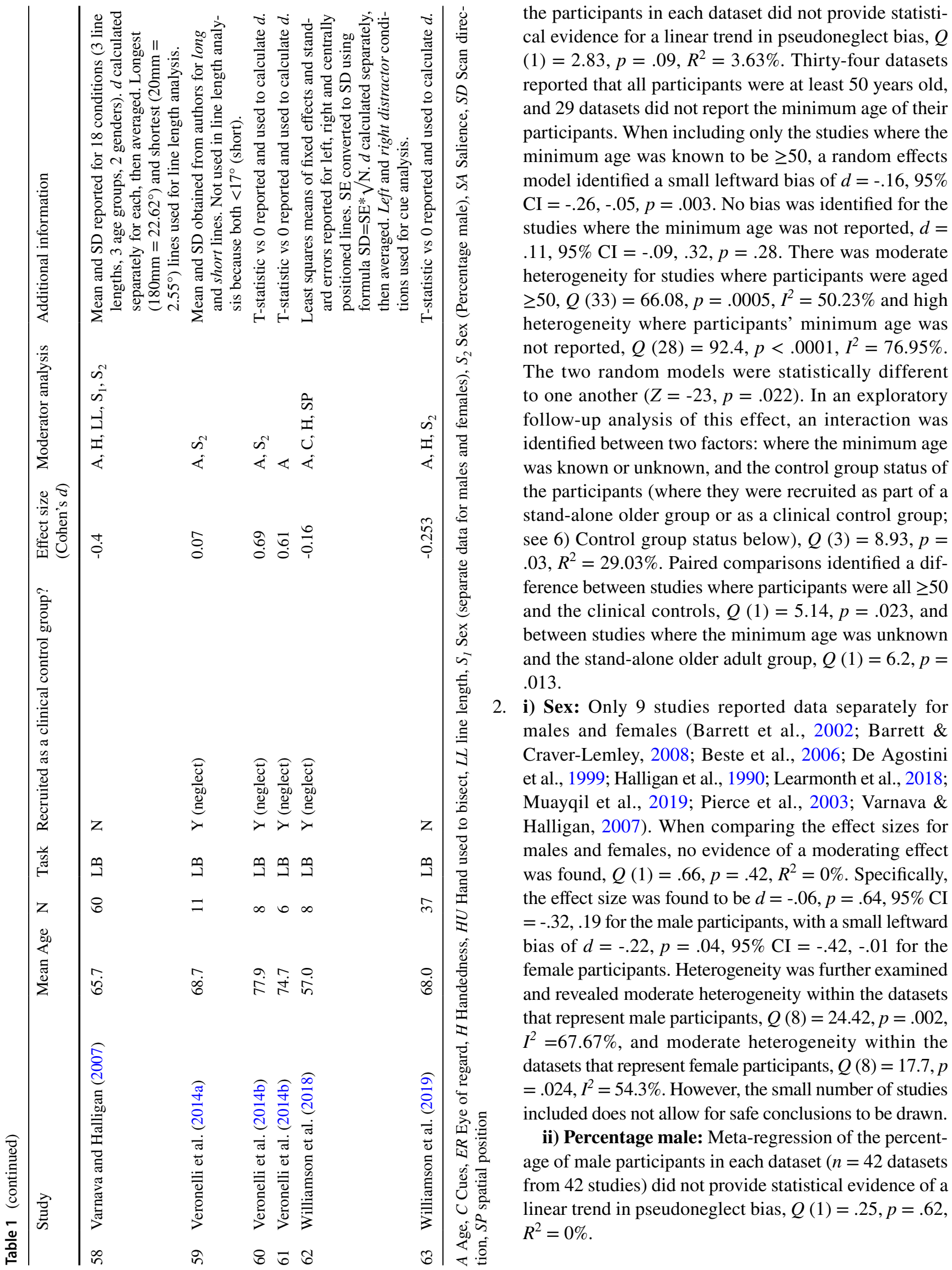


Table 2 Study characteristics of studies using the landmark task

Study Mean Age N Task Recruited as a clini- Effect size Moderator analysis Additional information
cal control group? (Cohen's d)

\begin{tabular}{|c|c|c|c|c|c|c|c|c|}
\hline 1 & Benwell et al. (2014) & 68.5 & 20 & LM & $\mathrm{N}$ & 0.15 & $\mathrm{~A}, \mathrm{H}, \mathrm{LL}, \mathrm{S}_{2}$ & $\begin{array}{l}\text { Raw data obtained from } \\
\text { authors. Long }(243 \mathrm{~mm} \\
\left.=19.69^{\circ}\right) \text { and short } \\
\left(24.3 \mathrm{~mm}=1.99^{\circ}\right) \text { lines } \\
\text { used in line length } \\
\text { analysis. }\end{array}$ \\
\hline 2 & Harvey et al. (2000) & 71.0 & 18 & LM & $\mathrm{N}$ & -0.26 & $\mathrm{~A}, \mathrm{C}, \mathrm{H}, \mathrm{S}_{2}$ & $\begin{array}{l}\text { T-statistic vs } 0 \text { reported for } \\
\text { left cue visible and right } \\
\text { cue visible conditions. } d \\
\text { calculated separately for } \\
\text { each, then averaged. }\end{array}$ \\
\hline 3 & Learmonth et al. (2017) & 68.8 & 19 & LM & $\mathrm{N}$ & 0.03 & A, H, LL, $\mathrm{S}_{1}, \mathrm{~S} 2$ & $\begin{array}{l}\text { Raw data obtained from } \\
\text { authors. } \mathrm{N}=1 \text { excluded } \\
\text { from analysis. Long } \\
\left(208.9 \mathrm{~mm}=14.88^{\circ}\right) \text { and } \\
\text { short }\left(20.7 \mathrm{~mm}=1.49^{\circ}\right) \\
\text { lines used in line length } \\
\text { analysis. }\end{array}$ \\
\hline 4 & Learmonth et al. (2018) & 70.4 & 39 & LM & $\mathrm{N}$ & -0.24 & $\mathrm{~A}, \mathrm{H}, \mathrm{S}_{1}, \mathrm{~S}_{2}$ & $\begin{array}{l}\text { Raw data obtained from } \\
\text { authors. }\end{array}$ \\
\hline 5 & $\begin{array}{l}\text { Schmitz and Peigneux } \\
\text { (2011) }\end{array}$ & 69.4 & 19 & LM & $\mathrm{N}$ & 0.45 & $\mathrm{~A}, \mathrm{H}, \mathrm{S}_{2}$ & $\begin{array}{l}\text { T-statistic against chance } \\
\text { (i.e., } 50 \% \text { "left longer") } \\
\text { reported and used to } \\
\text { calculate } d \text {. }\end{array}$ \\
\hline 6 & Zeller and Hullin (2018) & 75.0 & 59 & LM & $\mathrm{N}$ & 0.54 & $\mathrm{~A}, \mathrm{H}$ & $\begin{array}{l}\text { Cohen's d reported against } \\
\text { chance (i.e., 50\% "left } \\
\text { end closer"). }\end{array}$ \\
\hline
\end{tabular}

$A$ Age, $C$ Cues, $H$ Handedness, $L L$ line length, $S_{l}$ Sex (separate data for males and females), $S_{2}$ Sex (Percentage male)

3. Line length: Only 9 datasets (from 9 studies) reported data separately for the short and long line lengths (Binetti et al., 2011; Cowey et al., 1994; Ellis et al., 2006; Halligan et al., 1990; Kasai et al., 2016; Potter et al., 2000; Richard et al., 2004; Vallar et al., 2000; Varnava \& Halligan, 2007). There was no statistical evidence of a moderating effect of line length, $Q(1)=1.64, p=.20$, $R^{2}=4.48 \%$. Specifically, the effect size was found to be $d=.07,95 \% \mathrm{CI}=-.20, .35$ when the lines were long and $d=-.23,95 \% \mathrm{CI}=-.64, .18$ when the lines were short. Heterogeneity was further examined and revealed high levels of heterogeneity within the studies that used long lines, $Q(8)=30.06, p=.0002, I^{2}=69.88 \%$, and high levels within the studies that used short lines, $Q(8)=$ $41.88, p<.0001, I^{2}=85.8 \%$.

4. Spatial position: Only 9 datasets (from 8 studies) reported data separately for the position of the line (Beste et al., 2006; Ellis et al., 2006; Jeong et al., 2006; Learmonth et al., 2018; Mennemeier et al., 1997, 2001 (experiments 1 and 2); Potter et al., 2000; Williamson et al., 2018). No evidence of a moderating effect of line position was found, $Q(1)=1.10, p=.29, R^{2}=0 \%$. Specifically, the effect size was found to be $d=-.28,95 \%$
$\mathrm{CI}=-.58, .01$ when the line was positioned to the left and $d=.03,95 \% \mathrm{CI}=-.51, .57$ when the line was positioned to the right. Heterogeneity was further examined and revealed moderate heterogeneity within the datasets where the line was positioned to the left, $Q(8)=20.71$, $p=.008, I^{2}=70.57 \%$ and high heterogeneity within the datasets where the line was positioned to the right, $Q(8)=45.0, p<.0001, I^{2}=91.27 \%$. Similarly, the small number of studies included does not allow for safe conclusions to be drawn.

5. Cues: Six studies reported data separately for left- or right-sided cues (Drago et al., 2008a; 2008b; Falchook et al., 2015; Harvey et al., 2000; Mennemeier et al., 1997; Williamson et al., 2018). There was no statistical evidence of a moderating effect of cue direction, $Q(1)=.054, p=.46, R^{2}=$ $0 \%$. Specifically, the effect size was found to be $d=$ $-.09,95 \% \mathrm{CI}=-.36, .17$ when there were left-sided cues and $d=-.10,95 \% \mathrm{CI}=-.33, .54$ when there were right lateralized cues. Heterogeneity was further examined and revealed low levels of heterogeneity within the studies that provided left lateralized cues, $Q(5)=4.76, p=.45, I^{2}=11.41 \%$ and moderate 


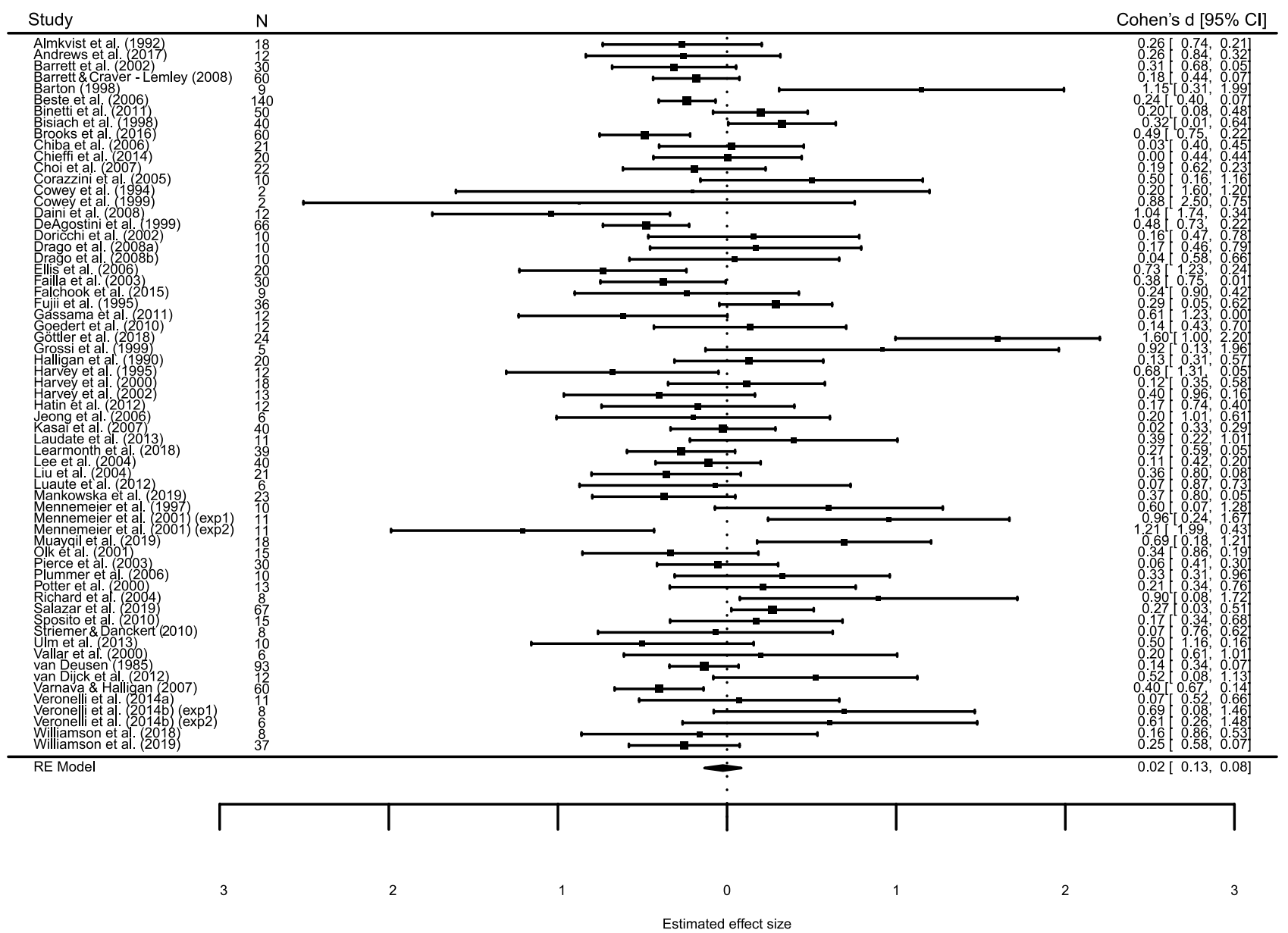

Fig. 2 Mean effect size (Cohen's d) and 95\% confidence intervals for the 63 datasets included in the line bisection meta-analysis

levels of heterogeneity within the studies that provided right lateralized cues, $Q(5)=14.09, p=$ $.02, I^{2}=63.68 \%$.

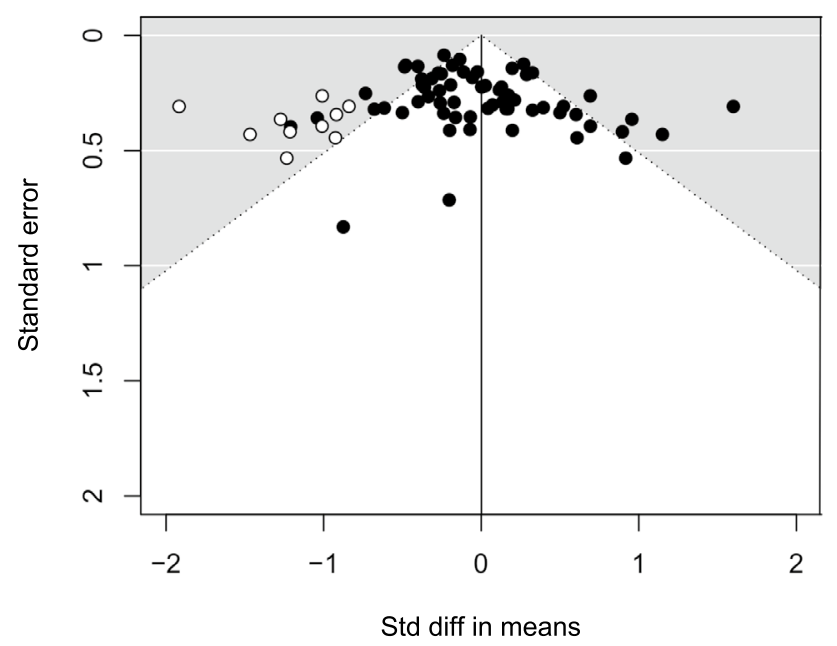

Fig. 3 Funnel plot of standard errors by standard difference in means. The white circles represent the 10 imputed studies to the left of centre
6. Control group status: There was marginal statistical evidence of a moderating effect of the participants' control group status (i.e., whether they were recruited as control participants for a clinical study or they were investigated as a stand-alone older adult group), $Q$

\begin{tabular}{|c|c|c|}
\hline Study & $\mathrm{N}$ & Cohen's d $[95 \% \mathrm{Cl}]$ \\
\hline Benwell et al. (2014) & $=$ & $0.15[-0.29,0.59]$ \\
\hline Harvey et al. (2000) & $18 \longmapsto$ & $-0.26[-0.73,0.21]$ \\
\hline Learmonth et al. (2017) & 19 & $0.03[-0.42,0.48]$ \\
\hline Learmonth et al. (2018) & $39 \mapsto$ & $-0.24[-0.56,0.07]$ \\
\hline Schmitz \& Peigneux (2011) & $\longrightarrow$ & $0.45[-0.02,0.92]$ \\
\hline Zeller \& Hullin (2018) & $r$ & $0.54[0.27,0.81]$ \\
\hline RE Model & & $0.12[-0.17,0.41]$ \\
\hline & \begin{tabular}{l|l|l} 
& 1 &
\end{tabular} & \\
\hline
\end{tabular}

Estimated effect size

Fig. 4 Mean effect size (Cohen's d) and 95\% confidence intervals for the 6 datasets included in the landmark task meta-analysis 
(1) $=3.97, p=.046, R^{2}=10.99 \%$. Specifically, the effect size was found to be $d=.006,95 \% \mathrm{CI}=-.10$, .23 when participants were controls to a clinical group (43 studies) and $d=-.17,95 \% \mathrm{CI}=-.28,-.05$ when they were healthy volunteers ( 20 studies). Heterogeneity was further examined and revealed moderate levels of heterogeneity within the studies that used controls to clinical groups, $Q(42)=120.12, p<.0001, I^{2}=$ $69.55 \%$, and moderate heterogeneity within the studies that used healthy volunteers, $Q(19)=44.64, p=.0008$, $I^{2}=59.67 \%$.

\section{Discussion}

We performed two meta-analyses to assess the evidence for a group-level lateralized spatial attention bias in adults aged 50 years old or older. Based on the prior meta-analysis of Jewell and McCourt (2000) and other studies (Benwell et al., 2014; Fujii et al., 1995; Fukatsu et al., 1990; Schmitz \& Peigneux, 2011; Stam \& Bakker, 1990), we hypothesised that older adults would exhibit a rightward spatial bias on the line bisection and landmark tasks (i.e., a mirrored bias relative to the leftward pseudoneglect that is typically observed in young adults). Separate meta-analyses were performed for the two spatial attention tasks and we also assessed the influence of six moderator variables: age, sex, line length, the spatial position of the line, the presence of left or right lateralised cues, and the control group status of the participants. A total of 69 datasets were included in the meta-analysis (63 in the line bisection analysis and 6 in the landmark analysis), comprising 1654 participants.

Overall, in contrast to our hypothesis, we identified no evidence of a lateralised bias in older adults for the line bisection task ( $d=-.09,95 \% \mathrm{CI}=-.19, .06)$. However, we identified a leftward line bisection bias for studies where all individual participants were known to be aged $\geq 50(d=$ $-.16,95 \% \mathrm{CI}=-.26,-.05, p=.003)$. There was no bias when the minimum age of participants was not reported $(d=.11$, $95 \% \mathrm{CI}=-.09, .32, p=.28$ ). This was a surprising finding because the inclusion of slightly younger participants would be expected to increase, rather than eliminate, a group-level leftward bias. Further exploration of the data suggested that this age effect was moderated by different participant characteristics across the two subgroups. The majority of studies in which the minimum age was not reported (and in which some participants may have been aged under 50) had also disproportionately been recruited as clinical controls $(n=24 / 29)$. This is important because clinical controls were found to have no bias to either side of space $(d=.006$, $95 \% \mathrm{CI}=-.10, .23)$. Conversely, around half $(n=16 / 34)$ of studies in which all of the participants were aged $\geq 50$ had been recruited as a stand-alone older adult group, a group in which we found a clear leftward bias $(d=-.17,95 \%$ CI $=-.28,-.05)$. This suggests that the leftward bias that we observed in the older group was not eliminated by the inclusion of potentially younger participants but that there may be additional, and as yet unquantified, characteristics of clinical control participants that are different to the typical older adult population. This issue is discussed further below.

Moderator analysis for the line bisection task indicated that spatial biases were not moderated by mean age, sex, line length, line position, or the presence of lateralised cues. The Egger's $t$-test identified a small study bias, a form of publication bias, in the line bisection literature with a small bias in favour of reporting rightward bisection errors. However, the corrected model indicated that the true effect size is likely to lie somewhere between $d=-.32$ and .01 which does retain the possibility of an eliminated bias after publication bias is accounted for. Taken together, we therefore tentatively estimate that spatial attention asymmetry in adults aged over 50 years old is likely to be slightly left of centre, similar to the pseudoneglect bias observed in young adults (Bowers \& Heilman, 1980). Finally, we found no evidence of a lateralised spatial bias for the landmark task, although the number of studies included in this analysis was small, thus this finding should be treated with caution $(n=6, d$ $=0.12,95 \% \mathrm{CI}=-0.17,0.44)$.

The observation of eliminated or reversed (i.e., rightward) spatial biases in seniors is often interpreted as evidence for either an asymmetry reduction, for example the HAROLD model of aging (Cabeza, 2002; Cabeza et al., 1997) or an advanced right hemisphere aging within the spatial attention networks (Goldstein \& Shelly, 1981). These models of aging were principally developed from neuroimaging evidence of cortical reorganisation during working memory tasks and have been co-opted into the lateralised spatial attention domain to explain potential age-related changes in spatial biases. We found no evidence of a rightward bias for either task which might indicate a reversed asymmetry in this age group. If such behavioural measures of spatial bias are indeed reflective of underlying cortical asymmetries, then our results hint that the right hemisphere may retain dominance for spatial attention relative to the left hemisphere into older age (see Brooks et al., 2016). However, it is important to note that our conclusions must remain limited to the line bisection and landmark tasks, given that spatial biases tend not to be consistent in either their direction or magnitude when assessed using different measures (Learmonth et al., 2015a, 2015b; Märker et al., 2019; Mitchell et al., 2020; Nicholls et al., 1999).

Spatial attention biases are both stimulus- and statedependent. The magnitude and direction of such biases are known to vary, for example in response to the presentation of different types of tasks (Brooks et al., 2016; Learmonth et al., 2015a; Luh et al., 1991; Nicholls et al., 1999), within-task features, such as the length of the bisected line (Benwell et al., 2014; Learmonth et al., 2017; 
Mennemeier et al., 2001), the viewing distance (Longo \& Lourenco, 2006), and participant characteristics, for example their handedness (De Agostini et al., 1999; Failla et al., 2003) and alertness (Bellgrove et al., 2004; Dufour et al., 2007; Manly et al., 2005). In contrast to computerised versions of the line bisection, landmark, greyscales and gratingscales tasks, paper and pencil versions of the line bisection task typically require that a motor action is performed, usually using one hand. It is therefore not trivial to dissociate the contribution of pure visuospatial attention asymmetries here from the asymmetry derived from this unilateral action. However, the majority of studies included in these meta-analyses involved participants using only their right hand to bisect the line, which would be expected to preferentially activate the left motor cortex and give rise to a weaker leftward bias than bisection performed using the left hand (De Agostini et al., 1999; Failla et al., 2003; Ochando \& Zago, 2018).

The meta-analysis of the line bisection task did not identify an influence of five of the six moderator variables that we included, namely age, sex, line length, the spatial position and the presence of left or right lateralised cues. In addition, we were unable to assess the effects of 7 variables that we had intended to analyse, either due to studies failing to report the necessary information (e.g., the percentage of left- and right-handers), or having identified too few studies that had experimentally manipulated the factor of interest in our target age group (e.g., the modality of line presentation, line salience, eye of regard, gaze direction, scanning direction, and body orientation). It is important to emphasise that the power of meta-analyses with respect to moderator variables relies on the number of studies that are included, rather than the number of participants. As such, these variables may yet be found to drive rightward shifts of spatial bias in older people, but we were unable to answer this question here. We recommend that further studies be performed to specifically assess the influence of these moderator variables, for studies to report their data by gender and handedness and also provide raw data to inform future meta-analyses.

The presence of a moderating effect of control group status was a surprising finding. We identified a small leftward bias in studies which had recruited a stand-alone group of older adults (e.g., in a comparison of young $v s$ older adults) but no bias in studies which had recruited older people as age-matched control participants in a clinical study. It is not immediately apparent what the reason for this difference might be, although there may be differences in the recruitment strategies adopted across the two groups. It may be that older people who are willing and able to attend university laboratories to take part in research studies are less representative of their peers across a range of characteristics (e.g., they may be healthier, more active, and better educated; Ganguli et al., 1998; Golomb et al., 2012). If these characteristics are protective against, or negatively correlated with, agerelated cortical reorganisation, we may not expect to see shifts in spatial bias in such a highly performing sample of older people. Clinicians should likewise aim to ensure that control participants are representative of the wider population when enrolling participants into clinical studies. In line with this, we recommend that older recruits be screened for cognitive decline (e.g., using the Montreal Cognitive Assessment; Nasreddine et al., 2005) and visual loss (see Learmonth et al., 2017) prior to taking part in spatial attention experiments. Given the small magnitude of asymmetries that are typically observed on the line bisection and landmark tasks, any pre-existing visual or cognitive impairments in this age group could reduce the precision of the bisection judgements that are made.

In addition to these screening measures, we recommend performing and pre-registering sample size calculations prior to commencing each study. Although we found that a minority of studies recruited a relatively large number of participants ( $n=60$ Barrett \& Craver-Lemley, (2008); $n=$ 140 Beste et al., (2006); $n=66$ De Agostini et al., (1999); $n=67$ Salazar et al., 2019; $n=93$ Van Deusen, (1983); $n$ = 60 Varnava \& Halligan, (2007); $n=59$ Zeller \& Hullin, (2018), the median sample size across all studies included in the analysis was only 15 participants. The standard statistical analyses that are performed in spatial bias experiments tend to be reliant upon a comparison of group-level means (e.g., one sample $t$-tests and analysis of variance). A high level of inter-individual variability of spatial bias is often observed in both young and older adults (Benwell et al., 2013; Learmonth et al., 2015a, 2015b; Märker et al., 2019; McCourt, 2001; Newman et al., 2014; Szczepanski \& Kastner, 2013), meaning that a large sample size is an important factor in obtaining a robust estimation of the mean bias. Under-recruitment is likely to result in studies that are susceptible to both false positive and false negative findings (Minarik et al., 2016) that may lead to a skewed estimation of spatial biases in the general population.

We acknowledge that there are a number of potential limitations to this meta-analysis. Although we found some evidence of a maintained directional spatial bias in older adults, we did not determine whether this bias is specifically reduced in magnitude compared to young adults. A meta-analysis to compare effect sizes obtained in the two age groups should now be undertaken to specifically address this question. Secondly, based on the methodology of Jewell and McCourt (2000), we included studies where the mean age was at least 50 years old. This is perhaps slightly young compared to many studies of age-related changes in spatial bias, which often use 60 years old as the lower bound, however, the mean age across all studies here was 69.3 years. Because we also failed to find a moderating influence of mean age in 
the line bisection analysis, we conclude that spatial bias is likely to be stable in the over-50s population, although we must also acknowledge that a considerable number of studies $(n=18)$ were excluded due to a lack of sufficient data available with which to derive an effect size.

Another potentially limiting factor is that we constrained our analysis to only two of the most commonly used measures of spatial attention bias, namely, the landmark and line bisection tasks. Our own prior research has highlighted that the magnitude and direction of spatial biases often do not correlate across different tasks in young adults (Brooks et al., 2016; Learmonth et al., 2018; Learmonth et al., 2015a; Luh, 1995; Nicholls et al., 1999) or in older adults (Märker et al., 2019). It is possible that alternative tasks, perhaps those involving luminance (e.g., greyscales; Mattingley et al., 1994) or spatial frequency judgements (e.g., gratingscales; Niemeier et al., 2007) are more effective in detecting subtle age-related changes in spatial bias compared to the line bisection and landmark tasks. However, a systematic review by Friedrich et al. (2016) suggests that this may not be the case, with the oldest adults tested (aged 80-89 years) exhibiting a stronger leftward bias on the greyscales task than young adults, aged 18-29. At present there are few studies available which detail older adult performance on these alternative tasks. Again, we recommend that additional studies be undertaken using these measures in order to adequately address this question.

\section{Conclusions}

In conclusion, we identified no overall spatial attention bias to either side of space, as indexed by the line bisection and landmark tasks, for studies where the mean page of participants was $\geq 50$ years old. However, there was a clear leftward line bisection bias for studies where all of the individual participants were known to be aged at least 50 and no bias for studies where the minimum age of participants was not reported. Secondly, a leftward line bisection bias was observed in studies where participants were recruited as a stand-alone older group, but there was no bias in studies where participants were clinical controls. No other moderating effects were identified and there was evidence of a small publication bias in favour of reporting rightward line bisection biases. These results suggest that older adults are likely to maintain a small leftward line bisection bias similar to young adults, but more studies are recommended in order to assess the potentially moderating influence of stimulus- and statedependent factors.

Open Access This article is licensed under a Creative Commons Attribution 4.0 International License, which permits use, sharing, adaptation, distribution and reproduction in any medium or format, as long as you give appropriate credit to the original author(s) and the source, provide a link to the Creative Commons licence, and indicate if changes were made. The images or other third party material in this article are included in the article's Creative Commons licence, unless indicated otherwise in a credit line to the material. If material is not included in the article's Creative Commons licence and your intended use is not permitted by statutory regulation or exceeds the permitted use, you will need to obtain permission directly from the copyright holder. To view a copy of this licence, visit http://creativecommons. org/licenses/by/4.0/.

\section{References}

\section{The references marked with an asterisk $(*)$ were included in the meta-analysis.}

*Almkvist, O., Basun, H., Wahlund, L. O., Andersson Lundman, G., \& Bäckman, L. (1992). White-matter hyperintensity and neuropsychological functions in dementia and healthy aging. Archives of Neurology, 49(6), 626-632. https://doi.org/10.1001/archneur. 1992.00530300062011

Andrade, K., Kas, A., Samri, D., Sarazin, M., Dubois, B., Habert, M.-O., $\&$ Bartolomeo, P. (2013). Visuospatial deficits and hemispheric perfusion asymmetries in posterior cortical atrophy. Cortex, 49(4), 940-947. https://doi.org/10.1016/j.cortex.2012.03.010

*Andrews, B., D'Avossa, G., \& Sapir, A. (2017). Aging changes 3D perception: Evidence for hemispheric rebalancing of lateralized processes. Neuropsychologia, 99, 121-127. https://doi.org/10. 1016/j.neuropsychologia.2017.03.005

Arduino, L. S., Veronelli, L., Cai, L., Xue, S., Corbo, M., \& Zhang, Y. (2016). Pseudoneglect in sentence bisection: a comparison between Italian and Chinese. Journal of Cognitive Psychology, 28(5), 575-584. https://doi.org/10.1080/20445911.2016.1170689

Baheux, K., Yoshizawa, M., \& Yoshida, Y. (2007). Simulating hemispatial neglect with virtual reality. Journal of Neuroengineering and Rehabilitation, 4, 27. https://doi.org/10.1186/ 1743-0003-4-27

Bailey, M. J., Riddoch, M. J., \& Crome, P. (2000). Evaluation of a test battery for hemineglect in elderly stroke patients for use by therapists in clinical practice. NeuroRehabilitation, 14(3), 139-150.

Balconi, M., Amenta, S., Sozzi, M., Cannatà, A. P., \& Pisani, L. (2013). Eye movement and online bisection task in unilateral patients with neglect: a new look to the "gradient effect." Brain Injury, 27(3), 310-317. https://doi.org/10.3109/02699052.2012.750739

*Barrett, A. M., \& Craver-Lemley, C. E. (2008). Is it what you see, or how you say it? Spatial bias in young and aged subjects. Journal of the International Neuropsychological Society, 14(4), 562-570. https://doi.org/10.1017/S1355617708080764.Is

*Barrett, A. M., Kim, M., Crucian, G. P., \& Heilman, K. M. (2002). Spatial bias: Effects of early reading direction on Korean subjects. Neuropsychologia, 40(7), 1003-1012. https://doi.org/10. 1016/S0028-3932(01)00147-6

*Barton, J. J. S., Behrmann, M., \& Black, S. (1998). Ocular search during line bisection. The effects of hemi-neglect and hemianopia. Brain, 121(6), 1117-1131. https://doi.org/10.1093/brain/ 121.6.1117

Bellgrove, M. A., Dockree, P. M., Aimola, L., \& Robertson, I. H. (2004). Attenuation of spatial attentional asymmetries with poor sustained attention. Neuroreport, 15(6), 1065-1069. https://doi. org/10.1097/00001756-200404290-00027 
*Benwell, C. S. Y., Thut, G., Grant, A., \& Harvey, M. (2014). A rightward shift in the visuospatial attention vector with healthy aging. Frontiers in aging neuroscience, 6, 113. https://doi.org/10.3389/ fnagi.2014.00113

Benwell, C. S. Y., Thut, G., Learmonth, G., \& Harvey, M. (2013). Spatial attention: differential shifts in pseudoneglect direction with time-on-task and initial bias support the idea of observer subtypes. Neuropsychologia, 51(13), 2747-56. https://doi.org/ 10.1016/j.neuropsychologia.2013.09.030

*Beste, C., Hamm, J. P., \& Hausmann, M. (2006). Developmental changes in visual line bisection in women throughout adulthood. Developmental Neuropsychology, 30(2), 753-767. https://doi. org/10.1207/s15326942dn3002

*Binetti, N., Aiello, M., Merola, S., Bruschini, M., Lecce, F., Macci, E., \& Doricchi, F. (2011). Positive correlation in the bisection of long and short horizontal Oppel-Kundt illusory gradients: Implications for the interpretation of the "cross-over" effect in spatial neglect. Cortex, 47(5), 608-616. https://doi.org/10.1016/j. cortex.2010.08.003

*Bisiach, E., Ricci, R., \& Mòdona, M. N. (1998). Visual Awareness and Anisometry of Space Representation in Unilateral Neglect: A Panoramic Investigation by Means of a Line Extension Task. Consciousness and Cognition, 7(3), 327-355. https://doi.org/10. 1006/ccog.1998.0361

Bourne, V. J., \& Gray, D. L. (2009). Hormone exposure and functional lateralisation: Examining the contributions of prenatal and later life hormonal exposure. Psychoneuroendocrinology, 34(8), 1214-1221. https://doi.org/10.1016/j.psyneuen.2009.03.010

Bowers, D., \& Heilman, K. M. (1980). Pseudoneglect: Effects of hemispace on a tactile line bisection task. Neuropsychologia, 18, 491-498. https://doi.org/10.1016/0028-3932(80)90151-7

*Brooks, J. L., Darling, S., Malvaso, C., \& Della Sala, S. (2016). Adult developmental trajectories of pseudoneglect in the tactile, visual and auditory modalities and the influence of starting position and stimulus length. Brain and Cognition, 103, 12-22. https://doi. org/10.1016/j.bandc.2015.12.001

Brooks, J. L., Sala, S. Della, \& Logie, R. H. (2011). Tactile rod bisection in the absence of visuo-spatial processing in children, mid-age and older adults. Neuropsychologia, 49(12), 33923398. https://doi.org/10.1016/j.neuropsychologia.2011.08.015

Cabeza, R. (2002). Hemispheric asymmetry reduction in older adults: the HAROLD model. Psychology and aging, 17(1), 85-100. https://doi.org/10.1037/0882-7974.17.1.85

Cabeza, R., Anderson, N. D., Locantore, J. K., \& McIntosh, A. R. (2002). Aging gracefully: Compensatory brain activity in highperforming older adults. NeuroImage, 17(3), 1394-1402. https:// doi.org/10.1006/nimg.2002.1280

Cabeza, R., Grady, C. L., Nyberg, L., McIntosh, A. R., Tulving, E., Kapur, S., et al. (1997). Age-related differences in neural activity during memory encoding and retrieval: A positron emission tomography study, 17(1), 391-400.

Chen, P., \& Goedert, K. M. (2012). Clock drawing in spatial neglect: A comprehensive analysis of clock perimeter, placement, and accuracy. Journal of Neuropsychology, 6(2), 270-289. https:// doi.org/10.1111/j.1748-6653.2012.02028.x

*Chiba, Y., Yamaguchi, A., \& Eto, F. (2006). Assessment of sensory neglect: A study using moving images. Neuropsychological Rehabilitation, 16(6), 641-652. https://doi.org/10. 1080/09602010543000073

*Chieffi, S., Iavarone, A., Iaccarino, L., La Marra, M., Messina, G., De Luca, V., \& Monda, M. (2014). Age-related differences in distractor interference on line bisection. Experimental Brain Research, 232(11), 3659-3664. https://doi.org/10.1007/ s00221-014-4056-0

*Choi, K. M., Lee, B. H., Lee, S. C., Ku, B. D., Kim, E. J., Suh, M. K., et al. (2007). Influence of moving background on line bisection performance in the normal elderly versus patients with hemispatial neglect. American Journal of Physical Medicine and Rehabilitation, 86(7), 515-526. https://doi.org/10.1097/PHM. 0b013e31806e0870

Çiçek, M., Deouell, L. Y., \& Knight, R. T. (2009). Brain activity during landmark and line bisection tasks. Frontiers in human neuroscience, 3, 1-8. https://doi.org/10.3389/neuro.09.007

*Corazzini, L. L., Geminiani, G., Stucchi, N., Gindri, P., \& Cremasco, L. (2005). Visual acceleration and spatial distortion in right brain-damaged patients. Experimental Brain Research, 161(3), 276-284. https://doi.org/10.1007/s00221-004-2068-x

Costantini, M., Frassinetti, F., Maini, M., Ambrosini, E., Gallese, V., \& Sinigaglia, C. (2014). When a laser pen becomes a stick: remapping of space by tool-use observation in hemispatial neglect. Experimental Brain Research, 232(10), 3233-3241. https://doi.org/10.1007/s00221-014-4012-z

*Cowey, A., Small, M., \& Ellis, S. (1994). Left visuo-spatial neglect can be worse in far than in near space. Neuropsychologia, 32(9), 1059-1066. https://doi.org/10.1016/0028-3932(94) 90152-X

*Cowey, A., Small, M., \& Ellis, S. (1998). No abrupt change in visual hemineglect from near to far space. Neuropsychologia, 37(1), 1-6. https://doi.org/10.1016/S0028-3932(98)00071-2

*Daini, R., Arduino, L. S., Di Menza, D., Vallar, G., \& Silveri, M. C. (2008). Line bisection and cerebellar damage. Cognitive and Behavioral Neurology, 21(4), 214-220. https://doi.org/10.1097/ WNN.0b013e318190d143

*De Agostini, M., Curt, F., Tzortzis, C., \& Dellatolas, G. (1999). Comparing left and right hand in line bisection at different ages. Developmental Neuropsychology, 15(3), 379-394. https://doi. org/10.1080/87565649909540756

Dolcos, F., Rice, H. J., \& Cabeza, R. (2002). Hemispheric asymmetry and aging: right hemisphere decline or asymmetry reduction. Neuroscience \& Biobehavioral Reviews, 26(7), 819-825. https:// doi.org/10.1016/S0149-7634(02)00068-4

*Doricchi, F., Onida, A., \& Guariglia, P. (2002). Horizontal space misrepresentation in unilateral brain damage II. Eye-head centered modulation of visual misrepresentation in hemianopia without neglect. Neuropsychologia, 40(8), 1118-1128. https://doi.org/10. 1016/S0028-3932(02)00011-8

*Drago, V., Foster, P. S., Ferri, R., Arico, D., Lanuzza, B., \& Heilman, K. M. (2008a). Distractibility and Alzheimer disease: The "neglected" phenomenon. Journal of Alzheimer's Disease, 15(1), 1-10. https:// doi.org/10.3233/JAD-2008-15101

*Drago, V., Foster, P. S., Skidmore, F. M., Kluger, B., Antoniello, D., \& Heilman, K. M. (2008b). Attentional grasp in Parkinson disease. Cognitive and Behavioral Neurology, 21(3), 138-142. https://doi.org/10.1097/WNN.0b013e3181864a35

Dufour, A., Touzalin, P., \& Candas, V. (2007). Time-on-task effect in pseudoneglect. Experimental Brain Research, 176(3), 532-7. https://doi.org/10.1007/s00221-006-0810-2

Duval, S., \& Tweedie, R. (2000). Trim and fill: A simple funnel-plot-based method of testing and adjusting for publication bias in meta-analysis. Biometrics, 56(2), 455-463. https://doi.org/10.1111/j.0006-341x. 2000.00455.x

Ebersbach, G., Trottenberg, T., Hättig, H., Schelosky, L., Schrag, A., \& Poewe, W. (1996). Directional bias of initial visual exploration. A symptom of neglect in Parkinson's disease. Brain, 119(1), 79-87. https://doi.org/10.1093/brain/119.1.79

*Ellis, A. W., Jordan, J. L., \& Sullivan, C. A. (2006). Unilateral neglect is not unilateral: Evidence for additional neglect of extreme right space. Cortex, 42(6), 861-868. https://doi.org/10.1016/S00109452(08)70429-5

*Failla, C. V., Sheppard, D. M., \& Bradshaw, J. L. (2003). Age and responding-hand related changes in performance of neurologically normal subjects on the line-bisection and chimeric-faces 
tasks. Brain and Cognition, 52(3), 353-363. https://doi.org/10. 1016/S0278-2626(03)00181-7

*Falchook, A. D., Salazar, L., Neal, D., Kesayan, T., Williamson, J. B., Malaty, I. A., et al. (2015). Global attentional neglect of segmented lines in Parkinson's disease. Neurocase, 21(4), 501-508.

Fink, G. R., Marshall, J. C., Weiss, P. H., \& Zilles, K. (2001). The Neural Basis of Vertical and Horizontal Line Bisection Judgments : An fMRI Study of Normal Volunteers. NeuroImage, 67(1 Pt 2), 59-67. https://doi.org/10.1006/nimg.2001.0819

Fisher, Z., Tipton, E., \& Zhipeng, H. (2017). Robumeta: Robust variance meta-regression. R package version 2.0.

Foxe, J. J., McCourt, M. E., \& Javitt, D. C. (2003). Right hemisphere control of visuospatial attention: line-bisection judgments evaluated with high-density electrical mapping and source analysis $\begin{array}{r}\text { ir. } \\ \text {. }\end{array}$ NeuroImage, 19(3), 710-726. https://doi.org/10.1016/S10538119(03)00057-0

Friedrich, T. E., Hunter, P. V., \& Elias, L. J. (2016). Developmental trajectory of pseudoneglect in adults using the greyscales task. Developmental Psychology, 52(11), 1937-1943. https://doi.org/ 10.1037/dev0000202

Friedrich, T. E., Hunter, P. V., \& Elias, L. J. (2018). The trajectory of pseudoneglect in adults: A systematic review. Neuropsychology Review, 28(4), 1-17. https://doi.org/10.1007/s11065-018-9392-6

*Fujii, T., Fukatsu, R., Yamadori, A., \& Kimura, I. (1995). Effect of age on the line bisection test. Journal of Clinical and Experimental Neuropsychology, 17(6), 941-4. https://doi.org/10.1080/ 01688639508402443

Fukatsu, R., Fujii, T., Kimura, I., Saso, S., \& Kogure, K. (1990). Effects of hand and spatial conditions on visual line bisection. The Tohoku Journal of Experimental Medicine, 161(4), 329-333.

Ganguli, M., Lytle, M. E., Reynolds, M. D., \& Dodge, H. H. (1998). Random versus volunteer selection for a community-based study. The Journals of Gerontology. Series A: Biological Sciences and Medical Sciences, 53(1), M39-46. https://doi.org/10.1093/ gerona/53a.1.m39

*Gassama, S., Deplancke, A., Saj, A., Honoré, J., \& Rousseaux, M. (2011). Do supine position and deprivation of visual environment influence spatial neglect? Journal of Neurology, 258(7), 1288-1294. https://doi.org/10.1007/s00415-011-5926-z

*Goedert, K. M., Leblanc, A., Tsai, S. W., \& Barrett, A. M. (2010). Asymmetrical effects of adaptation to left- and right-Shifting prisms depends on pPre-existing attentional biases. Journal of the International Neuropsychological Society, 16(5), 795-804. https://doi.org/10.1017/S1355617710000597

Goldstein, G., \& Shelly, C. (1981). Does the right hemisphere age more rapidly than the left? Journal of Clinical Neuropsychology, 3(1), 65-78. https://doi.org/10.1080/01688638108403114

Golomb, B. A., Chan, V. T., Evans, M. A., Koperski, S., White, H. L., \& Criqui, M. H. (2012). The older the better: are elderly study participants more non-representative? A cross-sectional analysis of clinical trial and observational study samples. BMJ open, 2(6), 1-6. https://doi.org/10.1136/bmjopen-2012-000833

*Göttler, J., Kaczmarz, S., Nuttall, R., Griese, V., Napiórkowski N., Kallmayer, M. et al. (2018). The stronger one-sided relative hypoperfusion, the more pronounced ipsilateral spatial attentional bias in patients with asymptomatic carotid stenosis. Journal of Cerebral Blood Flow and Metabolism, 1(14). https://doi. org/10.1177/0271678X18815790

*Grossi, D., Lepore, M., Esposito, A., Napolitano, A., Serino, M., \& Trojano, L. (1999). Neglect-associated constructional disorders: A paradoxical phenomenon? Neuropsychologia, 37(5), 589-594. https://doi.org/10.1016/S0028-3932(98)00110-9

Gutiérrez Pérez, C., Sävborg, M., Påhlman, U., Cederfeldt, M., Knopp, E., Nordlund, A., et al. (2011). High frequency of cognitive dysfunction before stroke among older people. International Journal of Geriatric Psychiatry, 26(6), 622-629. https://doi.org/10.1002/gps.2573
*Halligan, P. W., Manning, L., \& Marshall, J. C. (1990). Individual variation in line bisection: A study of four patients with right hemisphere damage and normal controls. Neuropsychologia, 28(10), 1043-1051. https://doi.org/10.1016/0028-3932(90)90139-F

*Harvey, M., Krämer-McCaffery, T., Dow, L., Murphy, P. J. S., \& Gilchrist, I. D. (2002). Categorisation of "perceptual" and "premotor" neglect patients across different tasks: Is there strong evidence for a dichotomy? Neuropsychologia, 40(8), 1387-1395. https://doi.org/10.1016/S0028-3932(01)00202-0

Harvey, M., Milner, A. D., \& Roberts, R. C. (1995a). Differential Effects of Line Length on Bisection Judgements in Hemispatial Neglect. Cortex, 31(4), 711-722. https://doi.org/10.1016/S00109452(13)80022-6

*Harvey, M., Milner, A. D., \& Roberts, R. C. (1995b). An investigation of hemispatial neglect using the landmark task. Brain and Cognition, 27(1), 59-78. https://doi.org/10.1006/brcg.1995.1004

*Harvey, M., Pool, T. D., Roberson, M. J., \& Olk, B. (2000). Effects of visible and invisible cueing procedures on perceptual judgments in young and elderly subjects. Neuropsychologia, 38(1), 22-31. https://doi.org/10.1016/S0028-3932(99)00055-X

*Hatin, B., Sykes Tottenham, L., \& Oriet, C. (2012). The relationship between collisions and pseudoneglect: Is it right? Cortex, 48(8), 997-1008. https://doi.org/10.1016/j.cortex.2011.05.015

Higgins, J. P. T., Thompson, S. G., Deeks, J. J., \& Altman, D. G. (2003). Measuring inconsistency in meta-analyses. BMJ, 327(7414), 557-560. https://doi.org/10.1136/bmj.327.7414.557

*Jeong, Y., Tsao, J. W., Efros, D. B., \& Heilman, K. M. (2006). Callosal neglect in hydrocephalus. Neurocase, 12(6), 346-349. https://doi.org/10.1080/13554790601100422

Jewell, G., \& McCourt, M. E. (2000). Pseudoneglect: a review and meta-analysis of performance factors in line bisection tasks. Neuropsychologia, 38(1), 93-110. https://doi.org/10.1016/ S0028-3932(99)00045-7

*Kasai, M., Ishizaki, J., \& Meguro, K. (2016). Alzheimer's patients do not show left unilateral spatial neglect but exhibit peripheral inattention and simplification. Dementia \& Neuropsychologia, 1(4), 374-380. https://doi.org/10.1590/s1980-57642008dn10400008

Kim, E. J., Kwon, H., Lee, B. H., Kim, G. H., Seo, S. W., \& Na, D. L. (2011). Attentional distractibility induced by optokinetic stimulation in mild cognitive impairment. Alzheimer Disease and Associated Disorders, 25(2), 155-158. https://doi.org/10.1097/ WAD.0b013e3181fa701e

*Laudate, T. M., Neargarder, S., \& Cronin-Golomb, A. (2013). Line bisection in Parkinson's disease: Investigation of contributions of visual field, retinal vision, and scanning patterns to visuospatial function. Behavioral Neuroscience, 127(2), 151-163. https://doi. org/10.1037/a0031618

*Learmonth, G., Benwell, C. S. Y., Thut, G., \& Harvey, M. (2017). Age-related reduction of hemispheric lateralisation for spatial attention: An EEG study. NeuroImage, 153, 139-151. https:// doi.org/10.1016/j.neuroimage.2017.03.050

Learmonth, G., Gallagher, A., Gibson, J., Thut, G., \& Harvey, M. (2015a). Intra- and inter-task reliability of spatial attention measures in pseudoneglect. PLoS One, 10(9), e0138379. https://doi. org/10.1371/journal.pone.0138379

*Learmonth, G., Märker, G., McBride, N., Pellinen, P., \& Harvey, M. (2018). Right-lateralised lane keeping in young and older British drivers. PLoS One, 13(9), 1-17. https://doi.org/10.1371/journal. pone. 0203549

Learmonth, G., Thut, G., Benwell, C. S. Y., \& Harvey, M. (2015b). The implications of state-dependent tDCS effects in aging: Behavioural response is determined by baseline performance. Neuropsychologia, 74, 1-12. https://doi.org/10.1016/j.neuropsychologia.2015. 01.037

Lee, A. C., Harris, J. P., Atkinson, E. A., \& Fowler, M. S. (2001). Evidence from a line bisection task for visuospatial neglect in left 
hemiparkinson's disease. Vision Research, 41(20), 2677-2686. https://doi.org/10.1016/s0042-6989(01)00129-8

Lee, A. C., Harris, J. P., Atkinson, E. A., Nithi, K., \& Fowler, M. S. (2002). Dopamine and the representation of the upper visual field: evidence from vertical bisection errors in unilateral Parkinson's disease. Neuropsychologia, 40(12), 2023-2029. https://doi. org/10.1016/s0028-3932(02)00055-6

*Lee, B. H., Kim, M., Kang, S. J., Park, K. C., Kim, E.-J.J., Adair, J. C., \& Na, D. L. (2004). Pseudoneglect in solid-line versus character-line bisection tasks: A test for attention dominance theory. Cognitive and Behavioral Neurology, 17(3), 174-178. https:// doi.org/10.1097/01.wnn.0000136592.83413.5f

Lee, Byung Hwa, Kang, E., Cho, S. S., Kim, E. J., Seo, S. W., Kim, G. M., et al. (2010). Neural correlates of hemispatial neglect: a voxel-based SPECT study. Cerebrovascular diseases, 30(6), 573-583. https://doi.org/10.1159/000319770

Levy, J., Trevarthen, C., \& Sperry, R. (1972). Perception of bilateral chimeric figures following hemispheric disconnexion. Brain, 95, 61-78.

*Liu, C. J., McDowd, J., \& Lin, K. C. (2004). Visuospatial inattention and daily life performance in people with Alzheimer's disease. American Journal of Occupational Therapy, 58(2), 202-210. https://doi.org/10.5014/ajot.58.2.202

Longo, M. R., \& Lourenco, S. F. (2006). On the nature of near space: Effects of tool use and the transition to far space. Neuropsychologia, 44(6), 977-981. https://doi.org/10.1016/j.neuropsychologia. 2005.09.003

*Luauté, J., Jacquin-Courtois, S., O’Shea, J., Christophe, L., Rode, G., Boisson, D., \& Rossetti, Y. (2012). Left-deviating prism adaptation in left neglect patient: Reflexions on a negative result. $\mathrm{Neu}$ ral Plasticity, 2012, 1-10. https://doi.org/10.1155/2012/718604

Luh, K. E. (1995). Line bisection and perceptual asymmetries in normal individuals: What you see is not what you get. Neuropsychology, 9(4), 435-448. https://doi.org/10.1037/0894-4105.9.4.435

Luh, K. E., Rueckert, L. M., \& Levy, J. (1991). Perceptual asymmetries for free viewing of several types of chimeric stimuli. Brain and Cognition, 16(1), 83-103. https://doi.org/10.1016/0278-2626(91) 90087-O

Luvizutto, G. J., Fogaroli, M. O., Theotonio, R. M., Moura Neto, E. D., Nunes, H. R. D. C., \& Bazan, R. (2020). Norm scores of cancelation and bisection tests for unilateral spatial neglect: data from a Brazilian population. Clinics, 75. https://doi.org/10.6061/ clinics/2019/e1468

*Mańkowska, A., Heilman, K. M., Williamson, J. B., Michałowski, J., \& Harciarek, M. (2019). Age-related changes in the allocation of spatially directed focal attention. Aging, Neuropsychology, and Cognition, OO(00), 1-17. https://doi.org/10.1080/13825585.2019. 1675581

Manly, T., Dobler, V. B., Dodds, C. M., \& George, M. A. (2005). Rightward shift in spatial awareness with declining alertness. Neuropsychologia, 43(12), 1721-8. https://doi.org/10.1016/j. neuropsychologia.2005.02.009

Märker, G., Learmonth, G., Thut, G., \& Harvey, M. (2019). Intra- and inter-task reliability of spatial attention measures in healthy older adults. PLoS One, 14(12), e0226424. https://doi.org/10.1371/ journal.pone.0226424

Mattingley, J. B., Bradshaw, J. L., Nettleton, N. C., \& Bradshaw, J. A. (1994). Can task specific perceptual bias be distinguished from unilateral neglect? Neuropsychologia, 32(7), 805-817. https:// doi.org/10.1016/0028-3932(94)90019-1

McCourt, M. E. (2001). Performance consistency of normal observers in forced-choice tachistoscopic visual line bisection. Neuropsychologia, 39(10), 1065-1076. https://doi.org/10.1016/S00283932(01)00044-6

McCourt, M. E., Garlinghouse, M., \& Reuter-Lorenz, P. A. (2005). Unilateral visual cueing and asymmetric line geometry share a common attentional origin in the modulation of pseudoneglect.
Cortex, 41(4), 499-511. https://doi.org/10.1016/s0010-9452(08) 70190-4

McCourt, M. E., Garlinghouse, M., \& Slater, J. (2000). Centripetal versus centrifugal bias in visual line bisection: focusing attention on two hypotheses. Frontiers In Bioscience, 5(D), 58-71. https:// doi.org/10.2741/a496

McCourt, M. E., \& Jewell, G. (1999). Visuospatial attention in line bisection: stimulus modulation of pseudoneglect. Neuropsychologia, 37(7), 843-855. https://doi.org/10.1016/S0028-3932(98) 00140-7

*Mennemeier, M., Rapcsak, S. Z., Pierce, C., \& Vezey, E. (2001). Crossover by line length and spatial location. Brain and Cognition, 47(3), 412-422. https://doi.org/10.1006/brcg.2001.1317

*Mennemeier, M., Vezey, E., Chatterjee, A., Rapcsak, S. Z., \& Heilman, K. M. (1997). Contributions of the left and right cerebral hemispheres to line bisection. Neuropsychologia, 35(5), 703-715. https://doi.org/10.1016/S0028-3932(96)00114-5

Milner, A. D., Brechmann, M., \& Pagliarini, L. (1992). To halve and to halve not: An analysis of line bisection judgements in normal subjects. Neuropsychologia, 30, 515-526. https://doi.org/10. 1016/0028-3932(92)90055-Q

Minarik, T., Berger, B., Althaus, L., Bader, V., Biebl, B., Brotzeller, F., et al. (2016). The importance of sample size for reproducibility of tDCS effects. Frontiers in Human Neuroscience, 10, 453. https://doi.org/10.3389/FNHUM.2016.00453

Mitchell, A. G., Harris, J. M., Benstock, S. E., \& Ales, J. M. (2020). The reliability of pseudoneglect is task dependent. Neuropsychologia, 148(August), 107618. https://doi.org/10.1016/j. neuropsychologia.2020.107618

Moher, D., Liberati, A., Tetzlaff, J., Altman, D. G., \& The PRISMA Group. (2009). Preferred Reporting Items for Systematic Reviews and Meta-Analyses: The PRISMA Statement. Annals of Internal Medicine, 151(4), 264-269. https://doi.org/10.7326/ 0003-4819-151-4-200908180-00135

*Muayqil, T. A., Al-Yousef, L. M., Al-Herbish, M. J., Al-Nafisah, M., Halawani, L. M., Al-Bader, S. S. et al. (2019). Culturally influenced performance on tasks of line bisection and symbol cancellation in Arabs. Applied Neuropsychology:Adult, 1(12). https:// doi.org/10.1080/23279095.2019.1627359

Nagamatsu, L. S., Carolan, P., Liu-Ambrose, T. Y. L., \& Handy, T. C. (2011). Age-related changes in the attentional control of visual cortex: A selective problem in the left visual hemifield. Neuropsychologia, 49(7), 1670-1678. https://doi.org/10.1016/j. neuropsychologia.2011.02.040

Nagamatsu, L. S., Liu-Ambrose, T. Y. L., Carolan, P., \& Handy, T. C. (2009). Are impairments in visual-spatial attention a critical factor for increased falls risk in seniors? An event-related potential study. Neuropsychologia, 47(13), 2749-2755. https://doi.org/10. 1016/j.neuropsychologia.2009.05.022

Nagamatsu, L. S., Munkacsy, M., Liu-Ambrose, T. Y. L., \& Handy, T. C. (2013). Altered visual-spatial attention to task-irrelevant information is associated with falls risk in older adults. Neuropsychologia, 51(14), 3025-3032. https://doi.org/10.1016/j. neuropsychologia.2013.10.002

Nasreddine, Z., Charbonneau, S., \& Cummings, J. L. (2005). The Montreal Cognitive Assessment, MoCA: a brief screening tool for mild cognitive impairment. Journal of the American Geriatrics Society, 53(4), 695-699. https://doi.org/10.1111/j.1532-5415. 2005.53221.x

Newman, D. P., Loughnane, G. M., Abe, R., Zoratti, M. T. R., Martins, A. C. P., van den Bogert, P. C., et al. (2014). Differential shift in spatial bias over time depends on observers' initial bias: Observer subtypes, or regression to the mean? Neuropsychologia, 64, 33-40. https://doi.org/10.1016/j.neuropsychologia.2014.09.017

Nicholls, M. E. R., Bradshaw, J. L., \& Mattingley, J. B. (1999). Freeviewing perceptual asymmetries for the judgement of brightness, 
numerosity and size. Neuropsychologia, 37(3), 307-14. https:// doi.org/10.1016/S0028-3932(98)00074-8

Niemeier, M., Stojanoski, B. B., \& Greco, A. L. (2007). Influences of time and spatial frequency on the perceptual bias: evidence for competition between hemispheres. Neuropsychologia, 45(5), 1029-40. https://doi.org/10.1016/j.neuropsychologia.2006.09. 006

Ochando, A., \& Zago, L. (2018). What are the contributions of handedness, sighting dominance, hand used to bisect, and visuospatial line processing to the behavioral line bisection bias? Frontiers in Psychology, 9(SEP), 1-8. https://doi.org/10.3389/fpsyg.2018. 01688

*Olk, B., Harvey, M., Dow, L., \& Murphy, P. J. S. (2001). Illusion processing in hemispatial neglect. Neuropsychologia, 39(6), 611-625. https://doi.org/10.1016/S0028-3932(00)00151-2

Olk, B., Wee, J., \& Kingstone, A. (2004). The effect of hemispatial neglect on the perception of centre. Brain and Cognition, 55(2), 365-367. https://doi.org/10.1016/j.bandc.2004.02.048

*Pierce, C. A., Jewell, G., \& Mennemeier, M. (2003). Are psychophysical functions derived from line bisection reliable? Journal of the International Neuropsychological Society, 9(1), 72-78. https:// doi.org/10.1017/s1355617703910083

Pizzamiglio, L., Committeri, G., Galati, G., \& Patria, F. (2000). Psychophysical properties of line bisection and body midline perception in unilateral neglect. Cortex, 36(4), 469-484. https://doi.org/ 10.1016/S0010-9452(08)70533-1

Pizzamiglio, L., Frasca, R., Guariglia, C., Incoccia, C., \& Antonucci, G. (1990). Effect of optokinetic stimulation in patients with visual neglect. Cortex, 26(4), 535-540. https://doi.org/10.1016/ s0010-9452(13)80303-6

*Plummer, P., Dunai, J., \& Morris, M. E. (2006). Understanding the effects of moving visual stimuli on unilateral neglect following stroke. Brain and Cognition, 60(2), 156-165. https://doi.org/10. 1016/j.bandc.2005.11.001

*Potter, J., Deighton, T., Patel, M., Fairhurst, M., Guest, R., \& Donnelly, N. (2000). Computer recording of standard tests of visual neglect in stroke patients. Clinical Rehabilitation, 14(4), 441-446. https://doi.org/10.1191/0269215500cr344oa

Reuter-Lorenz, P. A., \& Posner, M. I. (1990). Components of neglect from right-hemisphere damage: An analysis of line bisection. Neuropsychologia, 28(4), 327-333. https://doi.org/10.1016/ 0028-3932(90)90059-W

*Richard, C., Honoré, J., Bernati, T., \& Rousseaux, M. (2004). Straight-ahead pointing correlates with long-line bisection in neglect patients. Cortex, 40(1), 75-83. https://doi.org/10.1016/ S0010-9452(08)70921-3

Rousseaux, M., Bernati, T., Saj, A., \& Kozlowski, O. (2006). Ineffectiveness of prism adaptation on spatial neglect signs. Stroke, 37(2), 542-543. https://doi.org/10.1161/01.STR.0000198877. 09270.e8

*Salazar, R. D., Moon, K. L. M., Neargarder, S., \& Cronin-Golomb, A. (2019). Spatial judgment in Parkinson's disease: Contributions of attentional and executive dysfunction. Behavioral Neuroscience, 133(4), 350-360. https://doi.org/10.1037/bne0000329

Schenkenberg, T., Bradford, D. C., \& Ajax, E. T. (1980). Line bisection and unilateral visual neglect in patients with neurologic impairment. Neurology, 30(May), 509-517. https://doi.org/10.1212/ WNL.30.5.509

*Schmitz, R. R., \& Peigneux, P. (2011). Age-related changes in visual pseudoneglect. Brain and cognition, 76(3), 382-9. https://doi.org/ 10.1016/j.bandc.2011.04.002

*Sposito, A. V., Bolognini, N., Vallar, G., Posteraro, L., \& Maravita, A. (2010). The spatial encoding of body parts in patients with neglect and neurologically unimpaired participants.
Neuropsychologia, 48(1), 334-340. https://doi.org/10.1016/j. neuropsychologia.2009.09.026

Stam, C. J., \& Bakker, M. (1990). The prevalence of neglect: superiority of neuro-psychological over clinical methods of estimation. Clinical Neurology and Neurosurgery, 92(3), 229-235.

*Striemer, C. L., \& Danckert, J. (2010). Dissociating perceptual and motor effects of prism adaptation in neglect. NeuroReport, 21(6), 436-441. https://doi.org/10.1097/WNR.0b013e328338592f

Szczepanski, S. M., \& Kastner, S. (2013). Shifting attentional priorities: control of spatial attention through hemispheric competition. The Journal of Neuroscience, 33(12), 5411-21. https://doi.org/10. 1523/JNEUROSCI.4089-12.2013

*Ulm, L., Wohlrapp, D., Meinzer, M., Steinicke, R., Schatz, A., Denzler, P., et al. (2013). A circle-monitor for computerised assessment of visual neglect in peripersonal space. PLOS ONE, 8(12), 1-10. https://doi.org/10.1371/journal.pone.0082892

*Vallar, G., Daini, R., \& Antonucci, G. (2000). Processing of illusion of length in spatial hemineglect: A study of line bisection. Neuropsychologia, 38(7), 1087-1097. https://doi.org/10.1016/ S0028-3932(99)00139-6

*Van Deusen, J. (1983). Normative data for ninety-three elderly persons on the Schenkenberg line bisection test. Physical and Occupational Therapy in Geriatrics, 3(2), 49-54.

*van Dijck, J.-P., Gevers, W., Lafosse, C., \& Fias, W. (2012). The Heterogeneous Nature of Number-Space Interactions. Frontiers in Human Neuroscience, 5(January), 1-13. https://doi.org/10.3389/ fnhum.2011.00182

*Varnava, A., \& Halligan, P. W. (2007). Influence of age and sex on line bisection: A study of normal performance with implications for visuospatial neglect. Aging, Neuropsychology, and Cognition, 14(6), 571-585. https://doi.org/10.1080/13825580600826454

*Veronelli, L., Guasti, M. T., Arduino, L. S., \& Vallar, G. (2014a). Combining language and space: Sentence bisection in unilateral spatial neglect. Brain and Language, 137, 1-13. https://doi.org/ 10.1016/j.band1.2014.07.007

*Veronelli, L., Vallar, G., Marinelli, C. V., Primativo, S., \& Arduino, L. S. (2014b). Line and word bisection in right-brain-damaged patients with left spatial neglect. Experimental Brain Research, 232(1), 133-146. https://doi.org/10.1007/s00221-013-3726-7

Viechtbauer, W. (2007). Accounting for heterogeneity via randomeffects models and moderator analyses in meta-analysis. Zeitschrift für Psychologie/Journal of Psychology, 215(2), 104121. https://doi.org/10.1027/0044-3409.215.2.104

Wang, Q., Sonoda, S., Hanamura, M., Okazaki, H., \& Saitoh, E. (2005). Line bisection and rebisection: The crossover effect of space location. Neurorehabilitation and Neural Repair, 19(2), 84-92. https://doi.org/10.1177/1545968305274661

*Williamson, J. B., Lamb, D. G., Burtis, D. B., Haque, S., Zilli, M., E., Kesayan, T., , et al. (2018). Right hemispatial ipsilesional neglect with chronic right hemisphere strokes. Journal of Clinical and Experimental Neuropsychology, 40(4), 347-356. https://doi.org/ 10.1080/13803395.2017.1347606

*Williamson, J. B., Murphy, A., Lamb, D. G., Schwartz, Z., Szeles, D., Harciarek, M., et al. (2019). Improved accuracy on lateralized spatial judgments in healthy aging. Journal of the International Neuropsychological Society, 25(10), 1044-1050. https://doi.org/ $10.1017 / \mathrm{S} 1355617719000900$

*Zeller, D., \& Hullin, M. (2018). Spatial attention and the malleability of bodily self in the elderly. Consciousness and Cognition, 59, 32-39. https://doi.org/10.1016/j.concog.2018.01.006

Publisher's Note Springer Nature remains neutral with regard to jurisdictional claims in published maps and institutional affiliations. 